\title{
Analysis of Hemichannels and Gap Junctions: Application and Extension of the Passive Transmembrane Ion Transport Model
}

\author{
Wang Qiqian*a and Liu Shenquan ${ }^{\dagger a}$

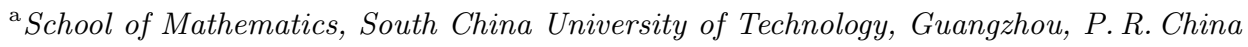

April 8, 2021

\begin{abstract}
Electrical synaptic transmission is an essential form of interneuronal communication which is mediated by gap junctions that permit ion flow. Three gene families (connexins, innexins and pannexins) have evolved to form gap junctional channels. Each gap junctional channel is formed by the docking of the hemichannel of one cell with the corresponding hemichannel of an adjacent cell. To date, there has been a lack of study models to describe this structure in detail. In this study, we demonstrate that numerical simulations suggest that the passive transmembrane ion transport model, based on the generality of ion channels, also applies to hemichannels in non-junctional plasma membranes. On this basis, we established a gap junctional channel model, which describes hemichannels' docking. We simulated homotypic and heterotypic gap junctions formed by connexins, innexins and pannexins. Based on the numerical results and our theoretical model, we discussed the physiology of hemichannels and gap junctions, including ion blockage of hemichannels, voltage gating of gap junctions and asymmetry and delay of electrical synaptic transmission, for which the numerical simulations are first comprehensively realised.
\end{abstract}

Keywords electrical synapse, gap junction, hemichannel, connexin, innexin, pannexin, docking, gating, permeability, conductance.

*First author: vincent_ong@foxmail.com

${ }^{\dagger}$ Corresponding author: mashqliu@scut.edu.cn 
20

\section{Introduction}

Electrical synaptic transmission is an essential form of interneuronal communication mediated by gap junctions. Not only do gap junctions underlie the functional processes in the mammalian central nervous system, but they also play a crucial role in the physiology of poikilothermic vertebrates.

\subsection{Gap Junctions}

The evolution of multicellularity necessitated interactions to coordinate cell activity. Specialised and distinct structures emerged independently to provide direct communication between cells, in plants, by plasmodesmata, in fungi, by septal pores and by gap junctions in animals.

Gap junctions are clusters of intercellular channels where each channel results from the docking of the hemichannel of one cell with the corresponding hemichannel of an adjacent cell, thus allowing passive ion transport. Through gap junctional channels, action potentials can rapidly spread between excitable cells, such as cardiomyocytes and neurons. However, at certain stages of development, gap junctions exist in all tissues. Action potentials are generated by ion flow, and the transmission of electrical signals is essentially the passive transport of ions.

Gap junctional channels are regulated by several physiological agents, including transjunctional voltage, and intracellular and extracellular calcium ions [1]. The unique architecture of gap junctional channels is considered to be influenced by the electrical field. Homotypic gap junctional channels show symmetrical bell-shaped steady-state $G_{\mathrm{j}} / V_{\mathrm{j}}$ curves, which can be described by the Boltzmann relation [2]. Based on a summary of experimental findings, the steady-state $G_{\mathrm{j}} / V_{\mathrm{j}}$ curves of heterotypic channels are generally asymmetric, with each hemichannel retaining roughly the properties of its homomeric combinations.

It is generally recognised that three gene families can form gap junctional channel$\mathrm{s}$ : connexins, innexins and pannexins. In vertebrates, most gap junctions are formed by connexins. In invertebrates, innexin homologues were identified. Subsequently, they were identified in vertebrate genomes. In mammals and many vertebrates, pannexin genes expressed in the brain have also been identified.

\subsection{Hemichannels}

Although it was previously believed that unpaired hemichannels remained closed, evidence has suggested that hemichannels can be voltage gated by depolarisation 
53 in non-junctional plasma membranes [3]. Nowadays, it is known that most of the ${ }_{54}$ connexins can form functional hemichannels under proper conditions [4], and so can 55 a series of innexins. However, although pannexins can form intercellular channels, 56 this does not occur often. Therefore, whether pannexin channels are hemichannels is 57 still controversial. [5]

\subsubsection{Connexins}

Vertebrate gap junctional channels are mainly composed of connexins that oligomerise intracellularly into connexons in the membrane. Connexons in adjacent cells pair up to form intercellular channels, resulting in a $2-3 \mathrm{~nm}$ separation between the junctional membranes, which is negligible compared to the radius of the cell.

Over the evolutionary history, gap junctions formed by connexons have developed diverse functions. Several studies have demonstrated that some connexons in cellular membranes do not take part in gap junction formation, and evidence suggests that a subset of unpaired connexins can form open hemichannels with their own functions, with their presence in non-junctional cellular membranes being widely established $[4]$.

\subsubsection{Innexins}

Under low resolution electron microscopy, the morphologies of gap junction channels from native tissues of vertebrates and invertebrates appear analogous. However, it is now known that two genetically distant genes code gap junction proteins. [6] Direct cellular communication in vertebrates occurs through connexin-based gap junctions, whereas innexins form gap junctional channels in invertebrates [7]. There is no significant sequence similarity between connexins and innexins, but some of their electrophysiological phenomena are similar. Whether connexins and innexins share a common ancestor or arose independently by convergent evolution remains to be determined. [6]

In addition to coordinating electrical activity, innexins' functions are diverse. For instance, Drosophila shak-B, an innexin gene, is known to additionally produce multiple products [8].

\subsubsection{Pannexins}

Highly unlike connexins, pannexins readily form single membrane channels, but does not often form intercellular channels. Although whether pannexin channels 
are hemichannels or not is still controversial, since they do form junction channels under some exceptional conditions [5], we still include them in the scope of study.

Pannexins are expressed in almost all tissues and are especially abundantly in the central nervous system of vertebrates. There are three pannexin genes (Px1, Px2 and Px3) in mammals [9]. Pannexin sequence is moderately similar to the innexins but not to connexins. The way connexins and pannexins form structures within cells are also different from each other. For example, Cx46 forms hexameric gap junctions, while Px1 forms a heptameric hemichannel. [10]

\subsection{Docking between hemichannels}

Hemichannels protrude approximately $20 \AA$ from the plasma membrane. Two hemichannels dock end-to-end to form a junctional channel. The binding reaction must be initiated by contact between hemichannels. This contact must be stable and sealed, exclude ions, and allow pore-opening.

The stability of the junctional channel structure suggests a tight interlocking arrangement between two paired hemichannels [11]. That is, the docking ends of paired hemichannels should be relatively fixed; therefore, state change of one must affect the other. Polarity reversal experiments also suggested that the gates on each side of a junctional channel were not independent, but were rather influenced by each other.

\subsection{Signal Transmission}

Gap junctional channels support direct communication between cells and are an integral part of signal transmission. For instance, all retinal cells communicate via gap junctions [12]. However, it is not well known how the hemichannels function to generate signal transmission and how the structure of gap junctions impacts the characteristics of signal transmission.

As mentioned above, each intercellular channel forms a pathway for direct ion transfer, thus generating an ion flow between cells. Although previously viewed as symmetrical channels, research on invertebrates has revealed that unique gap junction-forming proteins may asymmetrically contribute from each side of the synapse. Some findings suggest that this asymmetry could also exist in the vertebrate nervous systems [13]. This structural asymmetry generates functional asymmetry in ion flow through gap junctions [14]. 


\section{Foundation}

\subsection{Operators}

In this paper, we use several operation symbols for sequences and matrices to simplify expressions: $\left(a_{i, j}\right) \circ\left(b_{i, j}\right)=\left(a_{i, j} \cdot b_{i, j}\right),\left(a_{i}\right) \circ\left(b_{i, j}\right)=\left(b_{i, j}\right) \circ\left(a_{i}\right)=\left(a_{i} \cdot b_{i, j}\right)$, $\left(a_{i}\right) \circ\left(b_{i}\right)=\left(a_{i} \cdot b_{i}\right) ;\left(a_{i}\right)^{\circ\left(b_{i}\right)}=\left(a_{i}^{b_{i}}\right),\left(a_{i}\right)^{\circ b}=\left(a_{i}^{b}\right) ;\left(a_{i, j}\right) \oslash\left(b_{i, j}\right)=\left(a_{i, j} / b_{i, j}\right)$, $\left(a_{i}\right) \oslash\left(b_{i}\right)=\left(a_{i} / b_{i}\right) ; \sum\left(a_{i}\right)=\sum_{i} a_{i}, \sum\left(a_{i, j}\right)=\left(\sum_{i} a_{i, j}\right),\left(a_{i}\right)[k]=a_{k}$.

\subsection{Model of Passive Transmembrane Ion Transport}

Here, we briefly introduce the key elements of the passive transmembrane ion transport model. This model is based on the generality of ion channels and is applicable for various ion channels in different cells, such as plant cells, myocytes and neurocytes. A more detailed discussion, derivation and numerical experiments can be found in our previous paper [15].

As generally understood, an ion channel can be abstracted as a combination of filter and gate,

$$
\rho=f \circ g \circ \varrho,
$$

where $\boldsymbol{\rho}=\left(\rho_{h, i}\right), \rho_{h, i}$ is the selective permeability of channel $h$ for ion $i ; \boldsymbol{f}=\left(f_{h, i}\right)$, $f_{h, i}$ describes the filter of channel $h$ to ion $i ; \boldsymbol{g}=\left(g_{h}\right), g_{h}=v_{h} w_{h}$ describes the gate of channel $h$, and $\varrho=\left(\varrho_{h, i}\right), \varrho_{h, i}$ is the standard selective permeability of channel $h$ to ion $i$. Therefore, channel states can be described by $\boldsymbol{f}, \boldsymbol{v}$ and $\boldsymbol{w}$. When all external conditions remain constant, the states of channels tend to be stable,

$$
\lim _{t \rightarrow \infty}\left(\begin{array}{c}
\boldsymbol{v} \\
\boldsymbol{w} \\
f
\end{array}\right)=\left(\begin{array}{c}
\overline{\boldsymbol{v}} \\
\overline{\boldsymbol{w}} \\
\bar{f}
\end{array}\right)
$$

The stable states depend on the ionic flux (indicated by $\phi$ ) and internal ionic density (indicated by $\boldsymbol{\vartheta}$ ) detected by the channels,

$$
\left(\begin{array}{c}
\overline{\boldsymbol{v}} \\
\overline{\boldsymbol{w}} \\
\overline{\boldsymbol{f}}
\end{array}\right)=\mathscr{H}\left(\begin{array}{c}
\boldsymbol{\vartheta} \\
\boldsymbol{\phi}
\end{array}\right) \equiv\left[\begin{array}{c}
1-(\cos \boldsymbol{\vartheta})^{\circ \boldsymbol{\eta}} \\
\pi^{-1} \operatorname{acot} \boldsymbol{\phi} \oslash \boldsymbol{\vartheta} \\
\exp \left(-\boldsymbol{\kappa} \circ \boldsymbol{\vartheta}^{\circ 2}\right)
\end{array}\right] .
$$

where $\phi=\left(\phi_{h}\right)$, and $\phi_{h}$ points out the influence of detected ionic flux on density of channel $h ; \boldsymbol{\vartheta}=\left(\vartheta_{h}\right), \vartheta_{h}$ points out the difference between detected ionic density and optimal density of channel $h ; \boldsymbol{\eta}=\left(\eta_{h}\right), \eta_{h} \in(0, \infty)$ is the tolerance of channel $h$ to ionic density deviation, and describes the degree of which the channel allows the ion 
density to deviate from the optimal value; and $\boldsymbol{\kappa}=\left(\kappa_{h, i}\right), \kappa_{h, i}$ is the inactivation coefficient of channel $h$ occupied by ion $i$.

When we say $h \in \mathbf{H}$, we mean $h$ belongs to $\mathbf{H}$ channels. For example, when we say $h_{1} \in \operatorname{Px} 1$ and $h_{2} \in \mathrm{Px} 1$, we mean $h_{1}$ and $h_{2}$ are both Px1 channels. Obviously, $\operatorname{Px} 1 \cup \operatorname{Px} 2 \cup \operatorname{Px} 3 \subset \mathrm{Px}$.

\subsection{Fundamental Assumptions of Gap Junctions}

Summarising the previously presented information on gap junctions and hemichannels:

- Functional hemichannels in the non-junctional plasma membrane have their own functions.

- Each gap junctional channel is formed by the docking of a hemichannel in one cell with the corresponding hemichannel in an adjacent cell.

- The docking is stable and sealed, excludes ions and allows pore opening.

- Evidence exists for a dissociation between docking and opening. The gate of the hemichannel is supposed to lay at the intracellular end.

- The docking ends of paired hemichannels are relatively fixed; therefore, state change of one must affect the other.

- Hemichannels protrude approximately $20 \AA$ from the plasma membrane.

- There is a $2-3 \mathrm{~nm}$ separation between the junctional membranes.

Based on the above information, we made the following reasonable assumptions:

Assumption 1 Hemichannels conform to the basic assumptions of the passive transmembrane ion transport model.

Assumption 2 The docking is sealed such that ions do not leak from the junctions.

Assumption 3 The state of two paired hemichannels affect each other.

Assumption 4 The gap excludes external ions, and the gap distance is negligible.

According to Assumption 1, hemichannels can be described by the model of passive transmembrane ion transport. We now proceed to describe the model of the docking of paired hemichannels. 


\section{Model of Gap Junctional Channels}

As presented above, establishing a gap junctional channel model means establishing a model for the docking of two hemichannels. As such, we marked the corresponding hemichannel of $h$ as $h \boldsymbol{q}$. For convenience of presentation, we set $\boldsymbol{\top}\left(x_{h}\right)=\left(x_{h \boldsymbol{q}}\right)$. As the two cells are tightly connected, their internal charges also interact.

We mark the junctional channel formed by the docking of hemichannels $h_{1}$ and $h_{2}$ as $\left(h_{1}, h_{2}\right)$. For example, the docking of $h_{1}(\in \mathrm{Cx} 43)$ and $h_{2}(\in \mathrm{Cx} 46)$ forms $\left(h_{1}, h_{2}\right)$, which is a $\mathrm{Cx} 43 / \mathrm{Cx} 46$ gap junctional channel. In strict mathematical language, it should be written as $\mathrm{Cx} 43 \times \mathrm{Cx} 46$, but in this paper we will still follow the physiological idiom.

\subsection{Electric Field}

We previously discussed the ideal electric field distribution of a single cell [15]. We now calculate the electric field at a gap junction. The ionic density on both sides of the gap junction will then be deduced. According to Assumption 4, at a gap junction, the electric field arises from the electrons in the junctional cells, and the electric field between the junctional membranes (connected by hemichannels $h$ and $h$ q) can be considered as parallel,

$$
\mathscr{E}\left(\begin{array}{c}
\boldsymbol{c}_{h_{\boldsymbol{q}}} \\
\boldsymbol{c}_{h}
\end{array}\right) \equiv \frac{1}{2 \varepsilon} F \boldsymbol{z} \mathscr{Q}\left(\boldsymbol{c}_{h}-\boldsymbol{c}_{h \boldsymbol{q}}\right),
$$

where the direction goes from $h$ to $h \boldsymbol{q}, \boldsymbol{c}=\left(c_{i}\right), c_{i}$ is the concentration of ion $i$, and

$$
\mathscr{Q} c \equiv r^{-2} \int_{0}^{r} c \cdot x^{2} \mathrm{~d} x
$$

is the total amount of intracellular ions, where $r$ is the cell radius and $x$ is the distance to the centre of the cell. It is obvious that $\mathscr{E}\left(c_{h_{\boldsymbol{q}}} ; c_{h}\right)+\mathscr{E}\left(c_{h} ; c_{h_{\boldsymbol{q}}}\right)=0$. At the gap junction, the external ionic density does not need to be calculated, while the internal ionic density of $h$ is approximately

$$
\mathscr{S}_{\text {in }}\left(\begin{array}{c}
c_{h \boldsymbol{\sigma}} \\
\boldsymbol{c}_{h}
\end{array}\right) \equiv \boldsymbol{\lambda} \circ \mathscr{A}_{\text {in }} \boldsymbol{c}_{h} \circ\left[1-\mathscr{E}\left(\begin{array}{c}
\boldsymbol{c}_{h \boldsymbol{\sigma}} \\
\boldsymbol{c}_{h}
\end{array}\right) \cdot \boldsymbol{\lambda} \circ \frac{\boldsymbol{z} F}{2 R T}\right] \oslash\left[1+\mathscr{E}\left(\begin{array}{c}
\boldsymbol{c}_{h_{\boldsymbol{\sigma}}} \\
\boldsymbol{c}_{h}
\end{array}\right) \cdot \boldsymbol{\lambda} \circ \frac{\boldsymbol{z} F}{2 R T}\right],
$$

where

$$
\mathscr{A}_{\text {in }} \boldsymbol{c} \equiv 3 r^{-3} \int_{0}^{r} \boldsymbol{c} \cdot x^{2} \mathrm{~d} x
$$

is the average internal ion concentration (distribution). 


\section{$3.2 \quad$ Permeability}

For a channel $h$, in general, we can obtain the average permeability $\boldsymbol{\rho}_{h}$ on the membrane, where the surface area is $S_{h}$. The total permeability of the entire cell is

$$
\mathcal{P}_{h}=\rho_{h} S_{h}
$$

The docking of the two hemichannels is not a simple series connection, instead, the real situation is complex. We considered the unpaired hemichannel $h$ in the open state as a cylinder (radius of the cross section $r_{h}$, height $l_{h}$ ); After pairing, the two hemichannels $(h, h \boldsymbol{q})$ are connected to form a circular truncated cone (height $l_{h}+l_{h \boldsymbol{\Phi}}$, with cross section radiuses $r_{h}$ and $r_{h_{\uparrow}}$ ). It is easy to derive the axial conductivity for the circular truncated cone,

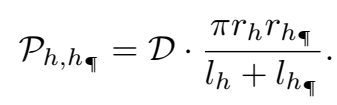

While the conductivity of a cylinder (unpaired hemichannel) is

$$
\mathcal{P}_{h}=\mathcal{D} \cdot \frac{\pi r_{h}^{2}}{l_{h}}
$$

If $l_{h}=l_{h}=l$, then

$$
\mathcal{P}_{h, h_{\uparrow}}=\frac{\left(\mathcal{P}_{h} \circ \mathcal{P}_{h_{\boldsymbol{\top}}}\right)^{\circ \frac{1}{2}}}{2} .
$$

According to Assumption 2, the ion flow from $h$ to $h$ 积 would be

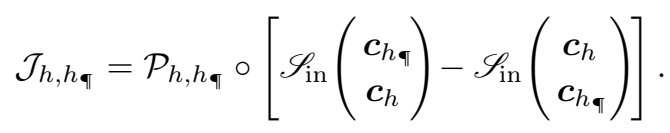

\subsection{Gating}

According to Assumption 3, the paired hemichannels $h$ and $h$ are not independent of each other. The state of one affects the other. In the model of passive transmembrane ion transport, the state of channel $h$ depends on $\vartheta_{h}$. When $\vartheta_{h}=0$, the channel tends to be at rest. Assuming that the torsion of $h$ by $h$ is 0 when hemichannel $h$ remains or tends to be at rest, as $\vartheta_{h}=0$, then a simple relationship would be

$$
\left(\begin{array}{c}
\overline{\boldsymbol{v}} \\
\overline{\boldsymbol{w}} \\
\overline{\boldsymbol{f}}
\end{array}\right)=\mathscr{H}\left[\begin{array}{c}
\boldsymbol{\vartheta}+\boldsymbol{\Phi}(\boldsymbol{u} \circ \boldsymbol{\vartheta}) \\
\boldsymbol{\phi}
\end{array}\right] .
$$

Here, $u_{h}(\geqslant 0)$ describes the effect of $h$ on $h \boldsymbol{q}$ in junctional channel $(h, h \boldsymbol{q})$. When $u_{h}=0, h$ has no effect on $h_{\boldsymbol{q}}$; the larger $u_{h}$ is, the greater the effect of $h$ on $h_{\boldsymbol{q}}$; the 
smaller $u_{h}$ is, the more the independence of $h_{\boldsymbol{q}}$. If $u_{h}$ is related to $\vartheta_{h}$, the greater the value of $\left|\vartheta_{h}\right|$, the more significant the effect of $h$ on $h$. Thereafter,

$$
u_{h}=\varpi_{h}\left|\vartheta_{h}\right|^{n_{h}}
$$

is a natural consequence, where the parameters $\left(\varpi_{h}, n_{h}\right)$ depend on the connection of $(h, h \boldsymbol{\Phi})$, and set $u_{h}=0$ (or $\left.\varpi_{h}=0\right)$ if $h$ is not paired. If $u_{h}=u_{h_{\boldsymbol{\Phi}}}=0, h$ and $h_{\boldsymbol{\Phi}}$ are completely independent. In particular, if $h$ and $h$ are symmetrical and the internal ion concentrations of the two cells are equal, then for any $V_{\mathrm{j}}$, there is $\vartheta_{h}=-\vartheta_{h}$. In this situation, if $u_{h}=u_{h \boldsymbol{\Phi}}=1$, then $\vartheta_{h}+u_{h_{\boldsymbol{\Phi}}} \vartheta_{h \boldsymbol{\Phi}}=0$ and $\vartheta_{h \boldsymbol{\Phi}}+u_{h} \vartheta_{h}=0$, according to Equation 12, both hemichannels $h$ and $h$ will lose their sensitivity completely. Hence, for a docking of $h$ and $h_{\boldsymbol{q}}$, there should be $u_{h}, u_{h_{\uparrow}} \in(0,1)$.

\subsection{Voltage and Current}

Considering a cell, we can estimate its membrane potential based on the intracellular ion concentrations,

$$
V_{\mathrm{m}}=\mathscr{V} \boldsymbol{c} \equiv \frac{F \delta_{\mathrm{m}}}{\varepsilon_{\mathrm{m}}} \boldsymbol{z} \mathscr{Q} c
$$

where $\delta_{\mathrm{m}}$ is the membrane thickness. Given a stimulation voltage $V_{\mathrm{s}}$, the stimulation current would be

$$
I_{\mathrm{s}}=\frac{V_{\mathrm{s}}-V_{\mathrm{m}}}{R_{\mathrm{s}}}
$$

where $R_{\mathrm{S}}$ is the electrode resistance. The detailed conversion methods of current and ionic flux are available in our previous study [15].

For a gap junction between two given cells $\mathrm{L}$ and $\mathrm{R}$, a double voltage-clamp procedure is commonly used to measure junctional current [16]. Each of the two cells is independently voltage-clamped. Typically, voltage steps $V_{\mathrm{s}(\mathrm{L})}$ are delivered to cell $\mathrm{L}$, while cell $\mathrm{R}$ is held at a constant potential, $V_{\mathrm{s}(\mathrm{R})}$. Junctional voltage is the difference between the membrane potentials of cells $\mathrm{L}$ and $\mathrm{R}$,

$$
V_{\mathrm{j}}=V_{\mathrm{m}(\mathrm{L})}-V_{\mathrm{m}(\mathrm{R})} .
$$

Further, there is a potential difference between the two voltage-clamps, denoted as

$$
\Delta V_{\mathrm{s}}=V_{\mathrm{s}(\mathrm{L})}-V_{\mathrm{s}(\mathrm{R})} .
$$

${ }_{231} V_{\mathrm{j}}$ always lags behind $\Delta V_{\mathrm{s}}$, and $V_{\mathrm{j}} \rightarrow \Delta V_{\mathrm{s}}$. Given a junctional channel, the junctional current can be calculated by junctional ionic flow,

$$
I_{\mathrm{j}}=F \boldsymbol{z} \mathcal{J} .
$$


Consequently, the conductance of this junctional current can be calculated by

$$
G_{\mathrm{j}}=\frac{I_{\mathrm{j}}}{V_{\mathrm{j}}} .
$$

This conductance is a virtual concept, a variable describing the state change in the junctional channel since a real conductor between the two cells does not actually exist.

\section{Results and Discussion}

\subsection{Unpaired Hemichannels}

External calcium ions can induce reversible conformational changes in hemichannel structure and affect the voltage sensitivity of gating, as the activation of hemichannels depends on $\left[\mathrm{Ca}^{2+}\right]_{\mathrm{ex}}[17]$. For example, extracellular calcium ion can block Cx32 hemichannels.

\subsubsection{Blockage and Sensitivity}

With an appropriate concentration of external solution, human Cx32 hemichannels expressed in Xenopus oocytes can be opened by raising the membrane potential. Additionally, variations in $\left[\mathrm{Ca}^{2+}\right]_{\mathrm{ex}}$ regulate $\mathrm{Cx} 32$ hemichannels. In normal ND96 solution $\left(\left[\mathrm{Ca}^{2+}\right]_{\mathrm{ex}}=1.8 \mathrm{mM},\left[\mathrm{Mg}^{2+}\right]_{\mathrm{ex}}=1 \mathrm{mM}\right)$, depolarising pulses slowly activate outward currents, which increase with the degree of depolarisation. With a return to the holding potential $\left(V_{\mathrm{m}}=-40 \mathrm{mV}\right)$, the currents turn inward and the hemichannels slowly close. When $\left[\mathrm{Ca}^{2+}\right]_{\mathrm{ex}}=5 \mathrm{mM}$, and $\left[\mathrm{Mg}^{2+}\right]_{\mathrm{ex}}=0 \mathrm{mM}$, the amplitudes of the hemichannel currents are maintained at a similar level. Substitution of external $\mathrm{Ca}^{2+}$ with $\mathrm{Mg}^{2+}$ also inhibits Cx32 hemichannel activation. It is worth noting that lowering $\left[\mathrm{Ca}^{2+}\right]_{\text {ex }}$ to $0.5 \mathrm{mM}$ increases the amplitudes of depolarisation-induced currents, more than two-fold. This increase is a sudden and large rise rather than a smooth change. $[17]$

The above phenomena observed in electrophysiological experiments (see Figure 19 for the actually recorded data) suggest that the external $\mathrm{Ca}^{2+}$ blocks voltage gating of Cx32 hemichannels, which can be effectively simulated with the passive transmembrane ion transport model (see Figure 1$)$, where the parameters $\left(w_{\mathrm{Cx} 32} \approx 0\right)$ indicate that it is actually the calcium and magnesium influxes that close the gate.

Based on the simulation results, it can be speculated that when the intracellular calcium ion concentration is extremely low, extracellular calcium ion blockage will 


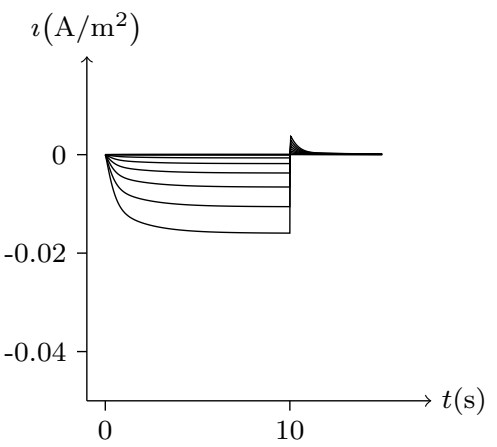

(A)

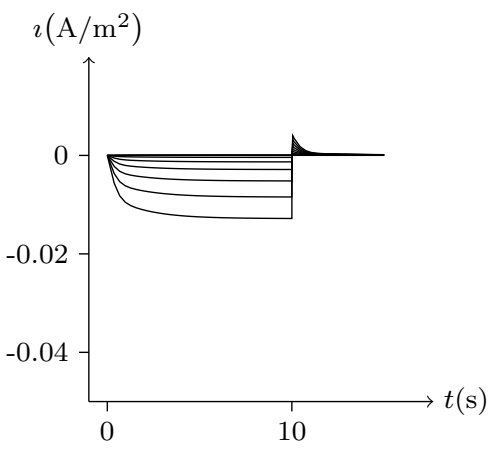

(C)

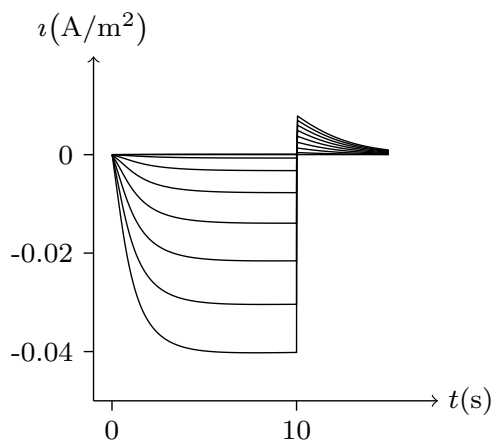

(B)

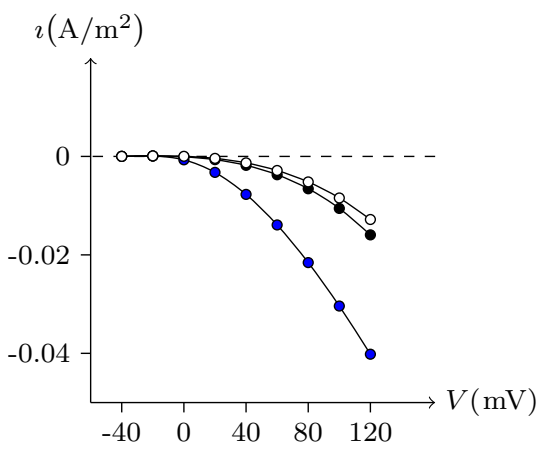

(D)

Figure 1: Simulated activating currents recorded from an isolated cell expressing $\mathrm{Cx} 32$ in normal, low and high $\left[\mathrm{Ca}^{2+}\right]_{\mathrm{ex}}$ bath solutions. Unpaired hemichannel: $\mathrm{Cx} 32$. Internal solution: I-1. Patch clamp: $R_{\mathrm{s}}=0.32 \mathrm{M} \Omega ; V_{\mathrm{s}}=-40 \mathrm{mV}$ for $t / \mathrm{s} \notin[0,10)$, $V_{\mathrm{s}}=-40 \mathrm{mV}$ to $120 \mathrm{mV}$ for $t / \mathrm{s} \in[0,10)$. (A) External solution: ND96 $\left(\left[\mathrm{Ca}^{2+}\right]=1.8 \mathrm{mM}\right.$, $\left.\left[\mathrm{Mg}^{2+}\right]=1.0 \mathrm{mM}\right)$. (B) External solution: ND96-1 $\left(\left[\mathrm{Ca}^{2+}\right]=0.5 \mathrm{mM}\right)$. (C) External solution: ND96-2 $\left(\left[\mathrm{Ca}^{2+}\right]=5.0 \mathrm{mM}\right)$. (D) The points are recorded at $V_{\mathrm{s}}=V$ and $t=10 \mathrm{~s}$, black for A, blue for $\mathrm{B}$ and white for $\mathrm{C}$. 
disappear, a situation observed in Cx43-expressing glioma cells. Hemichannel responses were triggered at $\left[\mathrm{Ca}^{2+}\right]_{\text {in }}<500 \mathrm{nM}$, and an elevation of $\left[\mathrm{Ca}^{2+}\right]_{\text {in }}$ triggered hemichannel opening. These responses disappeared with larger $\left[\mathrm{Ca}^{2+}\right]_{\text {in }}$ transients [18].

\subsubsection{Activation}

Figure 2 simulates the experiments of membrane currents from individual Xenopus oocytes expressing $\mathrm{Cx} 43$ and $\mathrm{Cx} 46$. Oocytes expressing $\mathrm{Cx} 43$ did not exhibit significant hemichannel activity. This is consistent with previous observations suggesting that $\mathrm{Cx} 43$ hemichannels have a very low opening probability in Barth's solution [18]. In contrast, depolarising pulses significantly activate outward currents of cells expressing Cx46. See Figure 20 for the actual recorded data.

In contrast to most connexin hemichannels, $\mathrm{Px} 1$ hemichannels are always active at physiological $\left[\mathrm{Ca}^{2+}\right]_{\mathrm{ex}}$, the reason for which can be found in model parameters. Take Cx32 as an example to compare with Px1. For $\bar{\sigma}_{\mathrm{Px} 1} \approx 3 \bar{\sigma}_{\mathrm{Cx} 32}$ (see Table 3 , where $\bar{\sigma}_{h}$ is the optimum density of $h$ ), Px1 channels tend to maintain an internal calcium ion density of about 3 times of that of Cx32 (magnesium-free). Hence at physiological $\left[\mathrm{Ca}^{2+}\right]_{\mathrm{ex}}, \mathrm{Px} 1$ would not be blocked by calcium ion influx when $V_{\mathrm{s}}>V_{\infty}$.

Further, the activation current curves of Px1 hemichannels are considerably different to those of the connexin family: Px1 hemichannels activate rapidly, and the ionic flux reaches its maximum in a distinctly short time. Outward currents are significant and consistent when $V_{\mathrm{s}}>-20 \mathrm{mV}$, reaching a peak within $(30,60) \mathrm{ms}$ and then slightly and slowly declining. This rectification became more pronounced with increasing of $V_{\mathrm{s}}[9]$. Figure 3 simulates these phenomena (see Figure 21 for the actual recorded data) using the model of passive transmembrane ion transport. Filter parameters $\boldsymbol{\gamma}$ and $\boldsymbol{\kappa}$ (see Table 1) indicate that the function of unpaired Px1 channels on ion transport is different from that of $\mathrm{Cx} 32, \mathrm{Cx} 43$ and $\mathrm{Cx} 46$. Decline in the ion selectivity of Px1 after activation is significant. In contrast, the ion selectivity of other hemichannels in this paper is essentially constant.

The above numerical simulations verified the applicability of the model of passive transmembrane ion transport to unpaired hemichannels. 


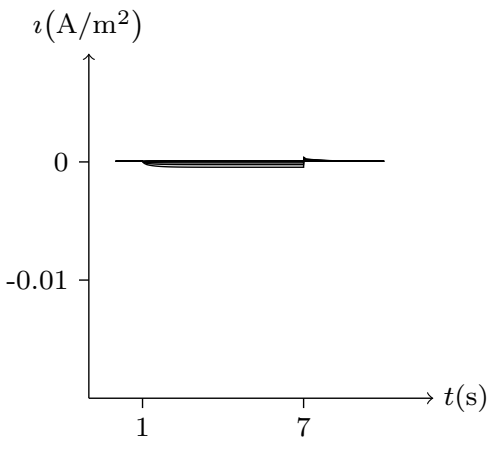

(A)

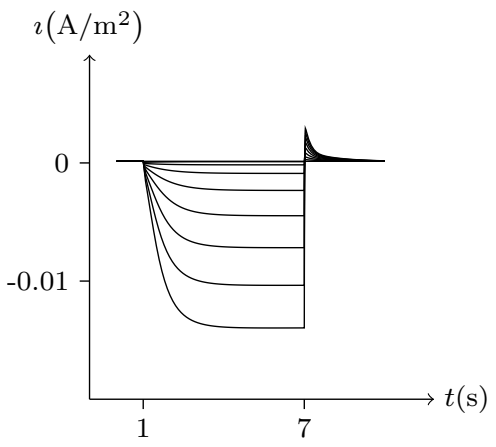

(B)

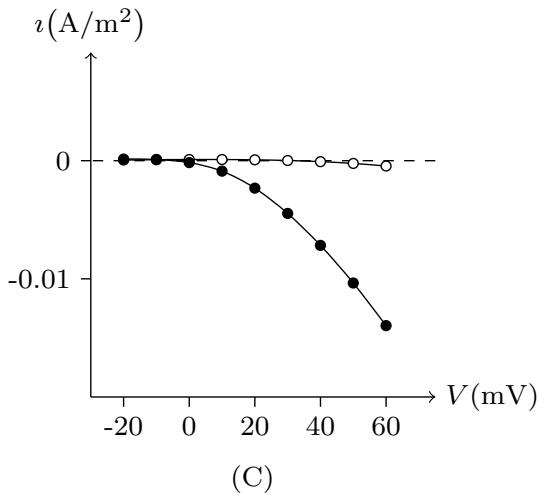

Figure 2: Numerical simulation of membrane currents recorded from individual cells expressing Cx43 and Cx46 individually, in response to depolarising voltage steps from a holding potential of $-20 \mathrm{mV}$, and stepped in $10 \mathrm{mV}$ increments from $-20 \mathrm{mV}$ to $+60 \mathrm{mV}$. Internal solution: I-2. External solution: Barth's. Patch clamp: $R_{\mathrm{s}}=1.0 \mathrm{M} \Omega ; V_{\mathrm{s}}=-20 \mathrm{mV}$ for $t / \mathrm{s} \notin[1,7), V_{\mathrm{s}}=-20 \mathrm{mV}$ to $60 \mathrm{mV}$ for $t / \mathrm{s} \in[1,7)$. (A) Unpaired hemichannel: Cx43. (B) Unpaired hemichannel: Cx46. (C) Current-voltage relationships for cells individually expressing $\mathrm{Cx} 43$ and $\mathrm{Cx} 46$. The points are recorded at $t=7 \mathrm{~s}$, white for $\mathrm{A}(\mathrm{Cx} 43)$ and black for $\mathrm{B}(\mathrm{Cx} 46)$. Compared to those for $\mathrm{Cx} 46$, the outward currents typical of hemichannel activity were absent from oocytes expressing $\mathrm{Cx} 43$. 


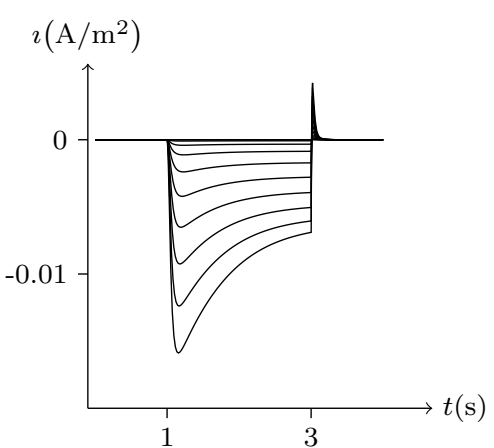

(A)

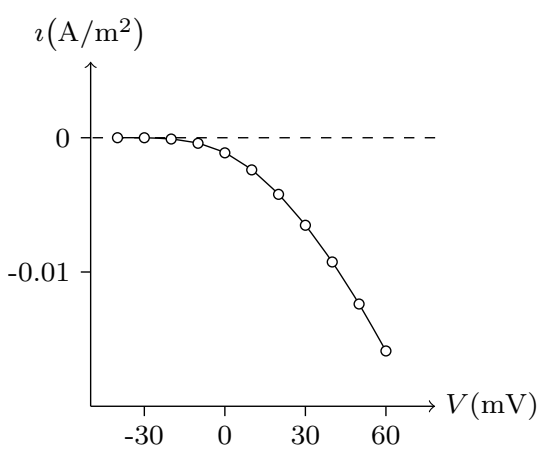

(B)

Figure 3: Simulated whole-cell membrane currents recorded from single cell expressing Px1. Unpaired hemichannel: Px1. External solution: ND96. Internal solution: I-3. Patch clamp: $R_{\mathrm{s}}=32 \mathrm{k} \Omega ; V_{\mathrm{s}}=-40 \mathrm{mV}$ for $t / \mathrm{s} \notin[1,3), V_{\mathrm{s}}=-40 \mathrm{mV}$ to $60 \mathrm{mV}$ for $t / \mathrm{s} \in[1,3)$. (A) Activating outward currents evoked by depolarising pulses. (B) Current-voltage relationship where points are recorded at the peaks for $t / \mathrm{s} \in[1,3)$. 


\subsection{Gap Junctions}

The permeabilities of gap junction channels are governed by hemichannels. The dependence of $G_{\mathrm{j}}$ (junctional conductance) on $V_{\mathrm{j}}$ (junctional voltage) has been extensively estimated. The conductance of all junctions is $V_{\mathrm{j}}$ sensitive because $V_{\mathrm{j}}$ is highly correlated with the ion distribution on both sides of the gap junctional channels. The model of gap junctional channels in this study can be used to explore the functional properties of gap junctions formed by various hemichannels combinations.

\subsubsection{Formed by Connexins}

For homotypic connexin-base gap junctional channel $\left(h, h_{\boldsymbol{q}}\right)$, hold $V_{\mathrm{j}}=0 \mathrm{mV}$, then $\boldsymbol{z} \mathscr{Q} \boldsymbol{c}_{h}=\boldsymbol{z} \mathscr{Q} \boldsymbol{c}_{h \boldsymbol{\tau}} \Rightarrow \mathscr{E}\left(\boldsymbol{c}_{h} ; \boldsymbol{c}_{h_{\boldsymbol{q}}}\right)=0$ and $\mathscr{E}\left(\boldsymbol{c}_{h_{\boldsymbol{q}}} ; \boldsymbol{c}_{h}\right)=0$. In this state, for homotypic

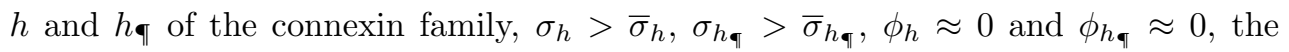
gap junctional channel remains open ( $\sigma_{h}$ is the detected ionic density of $h$ ). When $V_{\mathrm{j}}>0 \mathrm{mV}$ and gradually increased, calcium ions in cell $\mathrm{L}$ gathered towards the inner gate of hemichannel $h$, resulting in the increase of $g_{h}$ (gate opening degree of $h$ ), while hemichannel $h$ was the opposite, and finally led to the decline of the permeability of gap junctional channel $(h, h \boldsymbol{\uparrow})$ (calculated by Equation 10$)$. When both sides are symmetric, it can be derived that the $G_{\mathrm{j}}$ is maximal at $V_{\mathrm{j}}=0 \mathrm{mV}$ and it decreases more or less symmetrically at increasing $\left|V_{\mathrm{j}}\right|$ to lower nonzero conductance values (termed residual conductance). See Figures, 4, 6 and 7 for numerical simulation results, which are consistent with the electrophysiological experiment records (see Figures 23 and 24).

Considering human Cx32/Cx32 (simulated in Figures 4) and rat $\mathrm{Cx} 43 / \mathrm{Cx} 43$ junctions as examples (simulated in Figures 6), $\mathrm{Cx} 43 / \mathrm{Cx} 43$ junctional conductance changes more rapidly than $\mathrm{Cx} 32 / \mathrm{Cx} 32$ at the same $V_{\mathrm{j}}[19]$ (simulated in Figure 5). See Figure 22 for the actual recorded data.

The above simulations support that the gap junction model in this paper applies to homotypic junctions. Next, we examined whether the gap junction model could predict the properties of heteromeric junctions based on the parameters of homotypic junctions. Heterotypic gap junctions demonstrated asymmetries in voltage sensitivities [20], as the $G_{\mathrm{j}} / V_{\mathrm{j}}$ currents of heteromeric gap junctions are generally asymmetric of $V_{\mathrm{j}}=0$.

Immunocytochemical and immunoblot analyses of retinal pigment epithelial cells identified $\mathrm{Cx} 43$ and $\mathrm{Cx} 46$ as the connexins mediating gap junctional intercellular communication. Homotypic $(\mathrm{Cx} 43 / \mathrm{Cx} 43$ or $\mathrm{Cx} 46 / \mathrm{Cx} 46)$ or heterotypic $(\mathrm{Cx} 43 / \mathrm{Cx} 46)$ gap junctions may exist. Here, we simulated the response kinetics of gap junctions 


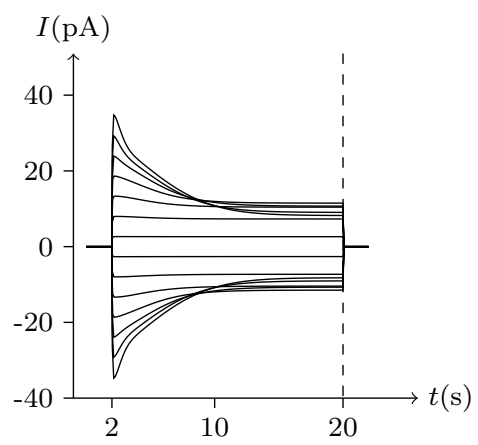

(A)

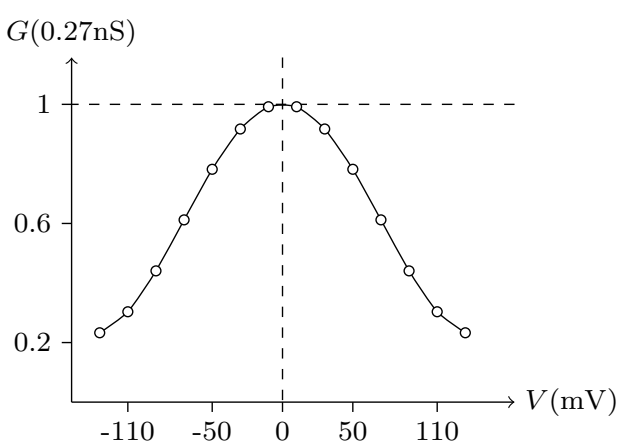

(A)

Figure 4: Simulated $V_{\mathrm{j}}$ gating property of $\mathrm{Cx} 32 / \mathrm{Cx} 32$ gap junctional channels. Gap junctional channel: $\mathrm{Cx} 32 / \mathrm{Cx} 32$. Internal and external solution: equal as in Figure 1. Patch clamps: $R_{\mathrm{s}(\mathrm{L})}=R_{\mathrm{s}(\mathrm{R})}=0.3 \mathrm{M} \Omega ; \Delta V_{\mathrm{s}}=0 \mathrm{mV}$ for $t / \mathrm{s} \notin[2,20), \Delta V_{\mathrm{s}}=-130 \mathrm{mV}$ to $+130 \mathrm{mV}$ for $t / \mathrm{s} \in[2,20)$. (A) Junctional currents induced by $V_{\mathrm{j}}$ pulses. (B) Graph of the steady-state $\left(V_{\mathrm{j}}, G_{\mathrm{j}}\right)$ relationship where points are recorded at $t=20 \mathrm{~s}$.

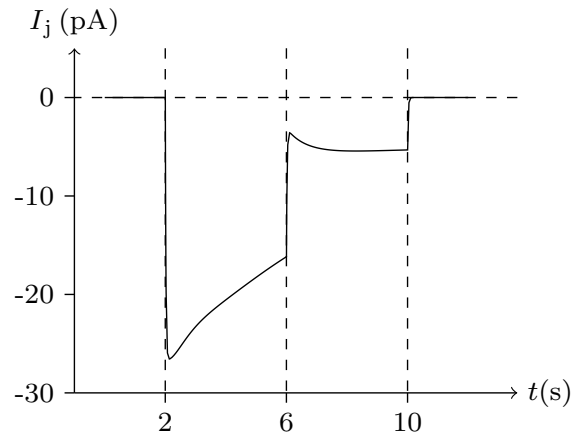

(A)

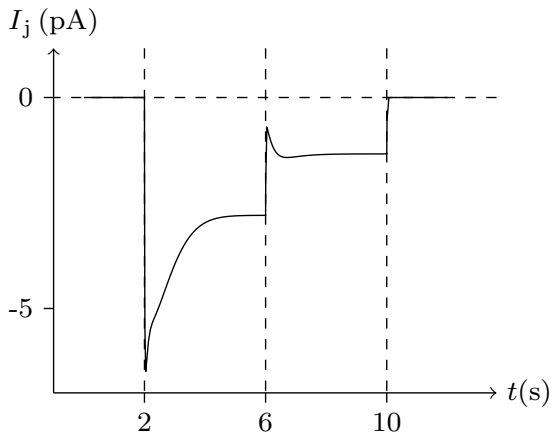

(B)

Figure 5: Numerical simulation of the comparison between $\mathrm{Cx} 32 / \mathrm{Cx} 32$ and $\mathrm{Cx} 43 / \mathrm{Cx} 43$ gap junctional channels. Patch clamps: $R_{\mathrm{s}}=0.3 \mathrm{M} \Omega ; \Delta V_{\mathrm{s}}=0 \mathrm{mV}$ for $t / \mathrm{s} \notin[2,10)$, $\Delta V_{\mathrm{s}}=100 \mathrm{mV}$ for $t / \mathrm{s} \in[2,6), \Delta V_{\mathrm{s}}=20 \mathrm{mV}$ for $t / \mathrm{s} \in[6,10)$. (A) Gap junctional channel: $\mathrm{Cx} 32 / \mathrm{Cx} 32$. External and internal solution: equal as in Figure 4. (B) Gap junctional channel: $\mathrm{Cx} 43 / \mathrm{Cx} 43$. External and internal solution: equal as in Figure 6. 


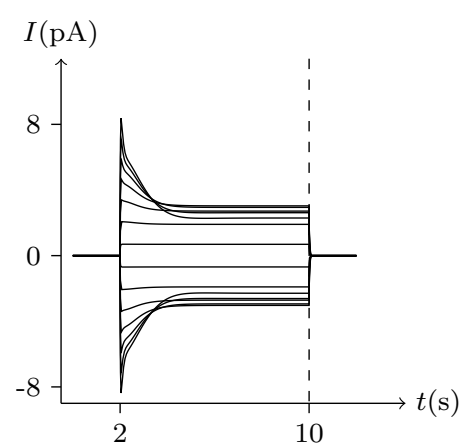

(A)

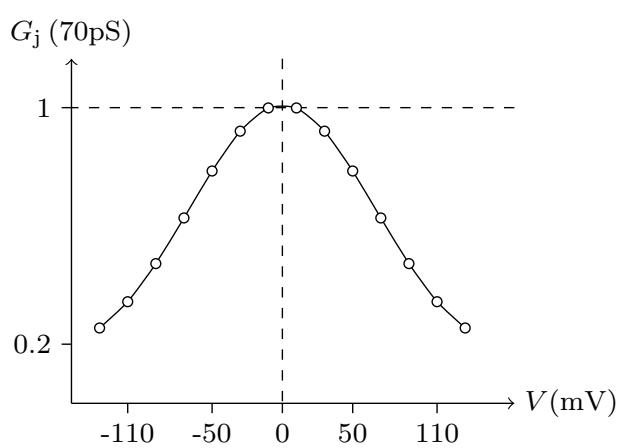

(B)

Figure 6: Simulated $V_{\mathrm{j}}$ gating property of $\mathrm{Cx} 43 / \mathrm{Cx} 43$ gap junctional channels. Gap junctional channel: $\mathrm{Cx} 43 / \mathrm{Cx} 43$. Internal and external solution: equal as in Figure 2. Patch clamps: $R_{\mathrm{s}(\mathrm{L})}=R_{\mathrm{s}(\mathrm{R})}=1 \mathrm{M} \Omega ; \Delta V_{\mathrm{s}}=0 \mathrm{mV}$ for $t / \mathrm{s} \notin[2,10), \Delta V_{\mathrm{s}}=-130 \mathrm{mV}$ to $+130 \mathrm{mV}$ for $t / \mathrm{s} \in[2,10)$. (A) Junctional currents induced by $V_{\mathrm{j}}$ pulses. (B) Graph of the steady-state $\left(V_{\mathrm{j}}, G_{\mathrm{j}}\right)$ relationship, where the points are recorded at $t=10 \mathrm{~s}$.

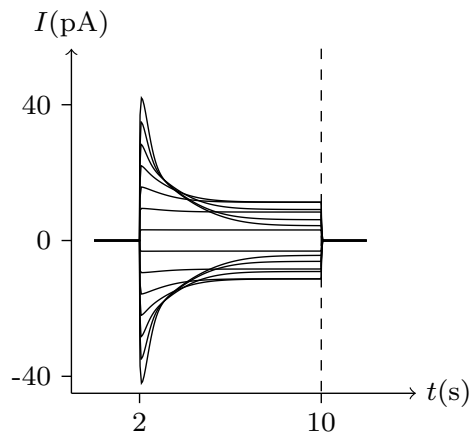

(A)

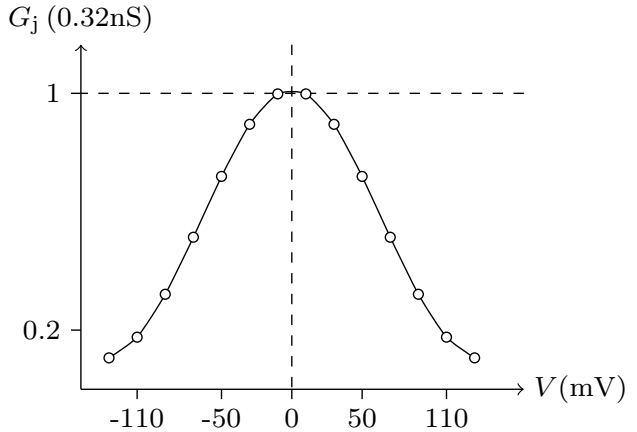

(B)

Figure 7: Simulated $V_{\mathrm{j}}$ gating property of $\mathrm{Cx} 46 / \mathrm{Cx} 46$ gap junctional channels. Gap junctional channel: $\mathrm{Cx} 46 / \mathrm{Cx} 46$. Internal and external solution: equal as in Figure 2. Patch clamps: $R_{\mathrm{s}(\mathrm{L})}=R_{\mathrm{s}(\mathrm{R})}=0.3 \mathrm{M} \Omega ; \Delta V_{\mathrm{s}}=0 \mathrm{mV}$ for $t / \mathrm{s} \notin[2,10), \Delta V_{\mathrm{s}}=-130 \mathrm{mV}$ to $+130 \mathrm{mV}$ for $t / \mathrm{s} \in[2,10)$. (A) Junctional currents induced by $V_{\mathrm{j}}$ pulses. (B) Graph of the steady-state $\left(V_{\mathrm{j}}, G_{\mathrm{j}}\right)$ relationship, where the points are recorded at $t=10 \mathrm{~s}$. 
formed by pairing cells expressing $\mathrm{Cx} 43$ and $\mathrm{Cx} 46$ individually.

In previous reports, no significant hemichannel currents were observed in cells expressing $\mathrm{Cx} 43$. In contrast, large outward hemichannel currents were observed in cells expressing Cx46 (simulated in Figure 2). Both Cx43 and Cx46 readily form homotypic gap junctions when expressed in Xenopus oocytes. The junctional conductances of $\mathrm{Cx} 43 / \mathrm{Cx} 43$ and $\mathrm{Cx} 46 / \mathrm{Cx} 46$ were similar and generally symmetric of $V_{\mathrm{j}}=0 \mathrm{mV}$. Conversely, the junctional conductances at $V_{\mathrm{j}}=-120 \mathrm{mV}$ revealed significant differences between these two connexin-based junctions. This phenomenon (see Figure 24) is very consistent with the results of our model simulation (see Figures 6 and 7 ).

On the other hand, $\mathrm{Cx} 43$ and $\mathrm{Cx} 46$ can also form heterotypic gap junctions. $G_{\mathrm{j}}$ of heterotypic $\mathrm{Cx} 43 / \mathrm{Cx} 46$ junctions were smaller than homotypic $\mathrm{Cx} 46 / \mathrm{Cx} 46$ junctions, suggesting that the building efficiency of heterotypic channels was lower. Furthermore, heterotypic $\mathrm{Cx} 43 / \mathrm{Cx} 46$ junctions displayed a much larger gating asymmetry than was predicted from $\mathrm{Cx} 43 / \mathrm{Cx} 43$ and $\mathrm{Cx} 46 / \mathrm{Cx} 46$ junctions [20]. However, based on our model of gap junctional channels, this gating asymmetry was indeed predictable. Substituting the parameters of $\mathrm{Cx} 43 / \mathrm{Cx} 43$ and $\mathrm{Cx} 46 / \mathrm{Cx} 46$ junctions into the model, the simulation results of $\mathrm{Cx} 43 / \mathrm{Cx} 46$ junctions (see Figure 8 ) are almost consistent with physiological experiments (see Figure 24).

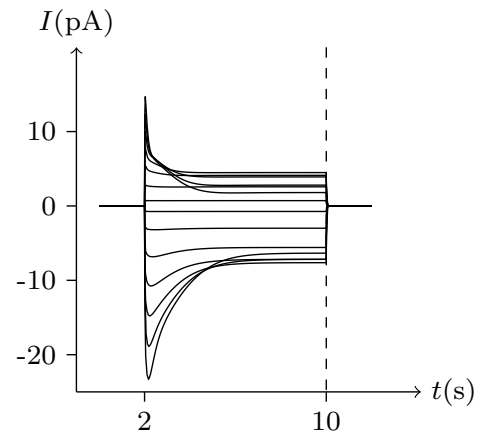

(A)

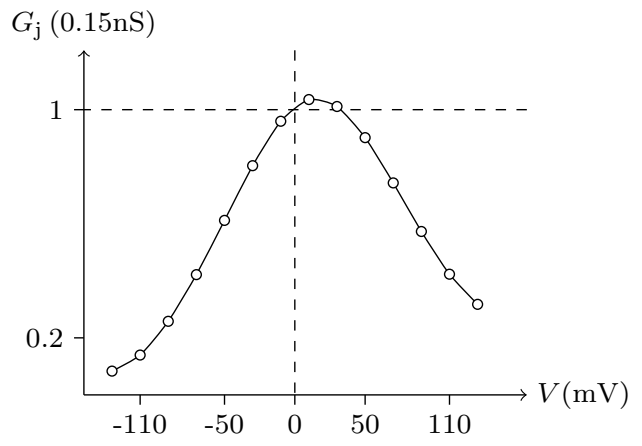

(B)

Figure 8: Simulated $V_{\mathrm{j}}$ gating property of $\mathrm{Cx} 43 / \mathrm{Cx} 46$ heterotypic junctional channels. Gap junctional channel: $\mathrm{Cx} 43 / \mathrm{Cx} 46$ (Cx43 expressed in cell L, Cx46 expressed in cell R). Internal and external solution: equal as in Figure 2. Patch clamps: $R_{\mathrm{s}(\mathrm{L})}=R_{\mathrm{S}(\mathrm{R})}=1.6 \mathrm{M} \Omega$; $\Delta V_{\mathrm{s}}=0 \mathrm{mV}$ for $t / \mathrm{s} \notin[2,10), \Delta V_{\mathrm{s}}=-130 \mathrm{mV}$ to $+130 \mathrm{mV}$ for $t / \mathrm{s} \in[2,10)$. (A) Junctional currents induced by $V_{\mathrm{j}}$ pulses. (B) Graph of the steady-state $\left(V_{\mathrm{j}}, G_{\mathrm{j}}\right)$ relationship, in which the points are recorded at $t=10 \mathrm{~s}$. 


\subsubsection{Formed by Innexins}

In neural systems, different variants of the innexin Shaking B (ShakB), expressed in adjacent cells, can form heterotypic gap junctions as rectifying electrical synapses. In Drosophila, rectifying electrical synapses are formed by ShakB neural +16 (ShakBN16) and ShakB Lethal (ShakBL). ShakBN16 is expressed presynaptically and ShakBL is expressed postsynaptically [14].

The voltage sensitivity of ShakBN16/ShakBN16 homotypic junctional channel$\mathrm{s}$ (see Figures $25 \mathrm{~F} \& \mathrm{I}$, simulated in Figure 10) is not significant. As $V_{\mathrm{j}}$ increases, steady-state $G_{\mathrm{j}}$ slightly rises. In contrast, steady-state $G_{\mathrm{j}}$ of ShakBL/ShakBL homotypic junctional channels (see Figures $25 \mathrm{H} \& \mathrm{~J}$, simulated in Figure 9) declines with increasing $\left|V_{\mathrm{j}}\right|[14]$.

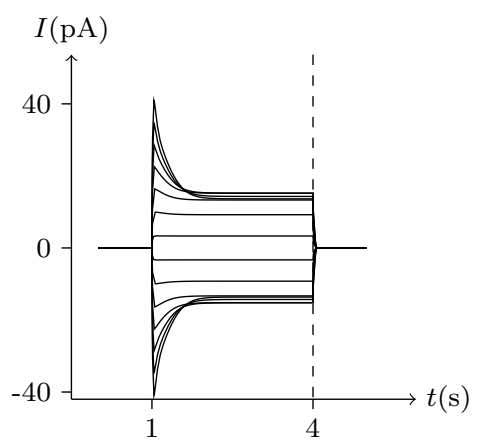

(A)

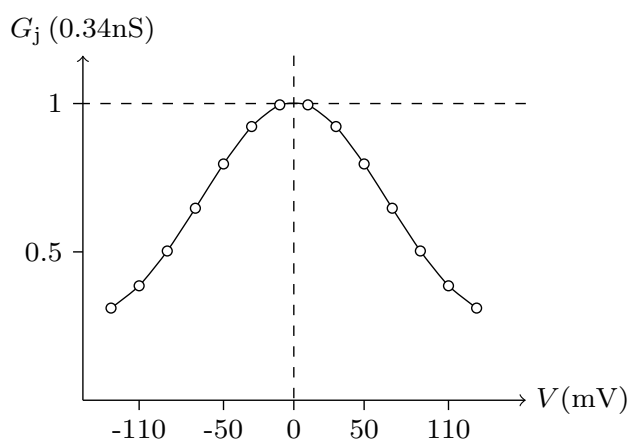

(B)

Figure 9: Simulated $V_{\mathrm{j}}$ gating property of ShakBL/ShakBL junctional channels. Gap junctional channel: ShakBL/ShakBL. Internal solution: I-2. External solution: Barth's. Patch clamps: $R_{\mathrm{s}(\mathrm{L})}=R_{\mathrm{s}(\mathrm{R})}=0.3 \mathrm{M} \Omega ; \Delta V_{\mathrm{s}}=0 \mathrm{mV}$ for $t / \mathrm{s} \notin[1,4), \Delta V_{\mathrm{s}}=-130 \mathrm{mV}$ to $+130 \mathrm{mV}$ for $t / \mathrm{s} \in[1,4)$. (A) Junctional currents induced by $V_{\mathrm{j}}$ pulses. (B) Graph of the steady-state $\left(V_{\mathrm{j}}, G_{\mathrm{j}}\right)$ relationship, in which the points are recorded at $t=4 \mathrm{~s}$.

ShakBL/ShakBN16 heterotypic junctional channels are asymmetrically gated in response to transjunctional voltage, which differs significantly from ShakBL/ShakBL and ShakBN16/ShakBN16 homotypic junctions (see Figures 25A-E). Depolarising $V_{\mathrm{s}}$ steps applied to the ShakBN16-expressing cells induced a large junctional current $I_{\mathrm{j}}$. By contrast, when ShakBL-expressing cells are subjected to depolarising $V_{\mathrm{s}}$, the induced current is of low magnitude. Figure 11 simulates the relationship between $G_{\mathrm{j}}$ and $V_{\mathrm{j}}$ for ShakBL/ShakBN16 heterotypic channels. Steady-state $G_{\mathrm{j}}$ increases in a sigmoidal fashion as the cells expressing ShakBN16 were depolarised or the ShakBL-expressing cells were hyperpolarised relative to their heterotypic partners.

For junctional channel $(h, h \boldsymbol{\uparrow})$, if both $u_{h}$ and $u_{h_{\boldsymbol{\uparrow}}}$ are close to 0 , as $h$ and $h_{\boldsymbol{q}}$ are 


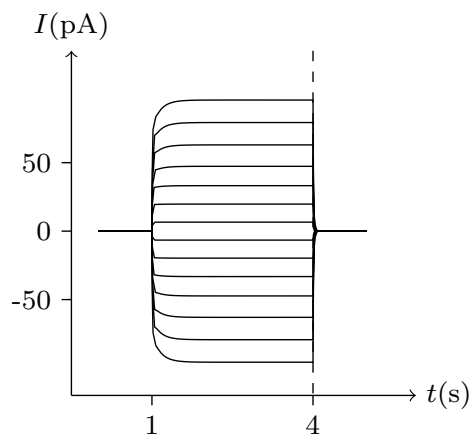

(A)

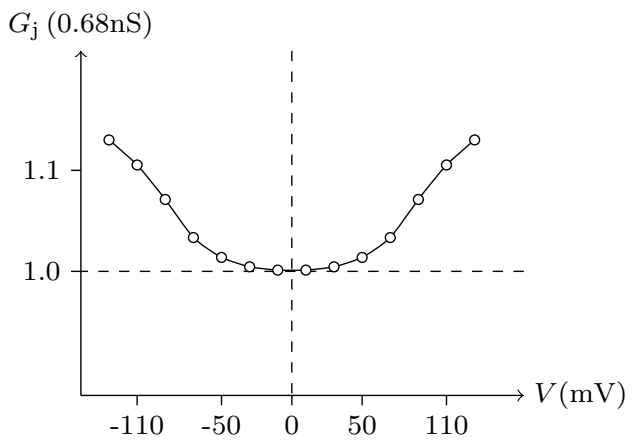

(B)

Figure 10: Simulated $V_{\mathrm{j}}$ gating property of ShakBN16/ShakBN16 junctional channels. Gap junctional channel: ShakBN16/ShakBN16. Internal solution: I-2. External solution: Barth's. Patch clamps: $R_{\mathrm{s}(\mathrm{L})}=R_{\mathrm{s}(\mathrm{R})}=0.3 \mathrm{M} \Omega ; \Delta V_{\mathrm{s}}=0 \mathrm{mV}$ for $t / \mathrm{s} \notin[1,4), \Delta V_{\mathrm{s}}=$ $-130 \mathrm{mV}$ to $+130 \mathrm{mV}$ for $t / \mathrm{s} \in[1,4)$. (A) Junctional currents induced by $V_{\mathrm{j}}$ pulses. (B) Graph of the steady-state $\left(V_{\mathrm{j}}, G_{\mathrm{j}}\right)$ relationship, in which the points are recorded at $t=4 \mathrm{~s}$.

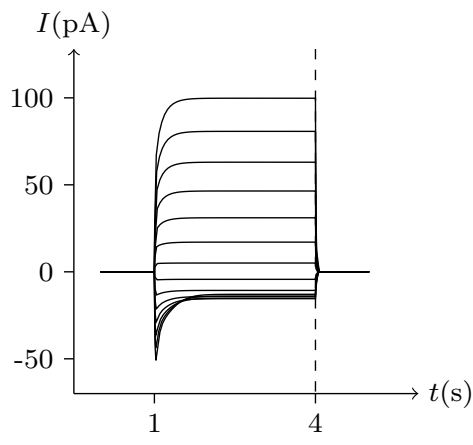

(A)

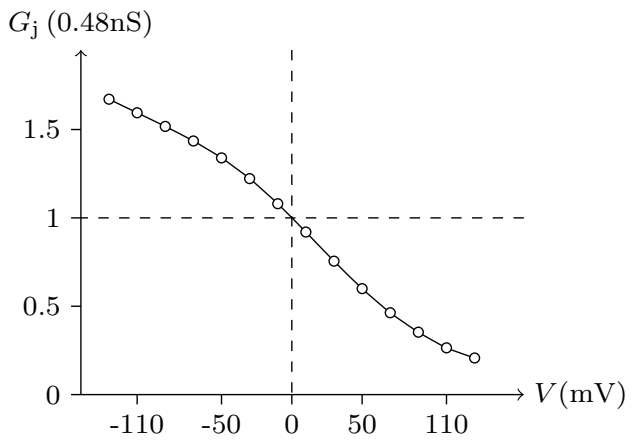

(B)

Figure 11: Simulated $V_{\mathrm{j}}$ gating property of ShakBL/ShakBN16 junctional channels. Gap junctional channel: ShakBL/ShakBN16 (ShakBL expressed in cell L, ShakBN16 expressed in cell R). Internal solution: I-2. External solution: Barth's. Patch clamps: $R_{\mathrm{s}(\mathrm{L})}=R_{\mathrm{s}(\mathrm{R})}=$ $0.3 \mathrm{M} \Omega ; \Delta V_{\mathrm{s}}=0 \mathrm{mV}$ for $t / \mathrm{s} \notin[1,4), \Delta V_{\mathrm{s}}=-130 \mathrm{mV}$ to $+130 \mathrm{mV}$ for $t / \mathrm{s} \in[1,4)$. (A) Junctional currents induced by $V_{\mathrm{j}}$ pulses. (B) Graph of the steady-state $\left(V_{\mathrm{j}}, G_{\mathrm{j}}\right)$ relationship, where the points are recorded at $t=4 \mathrm{~s}$. 


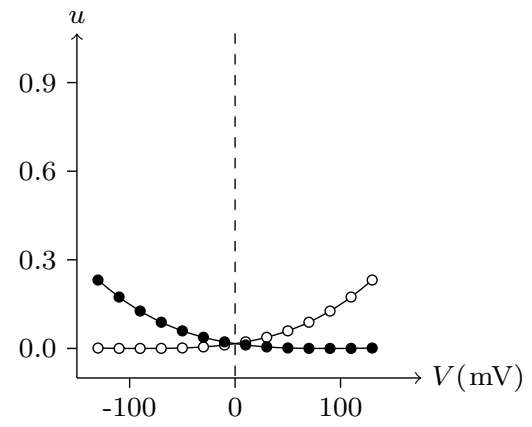

(A) $\mathrm{Cx} 32 / \mathrm{Cx} 32$

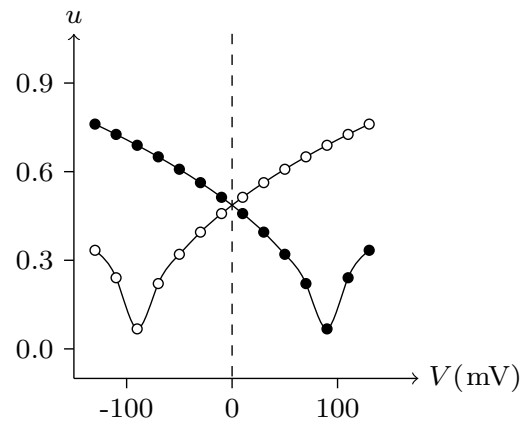

(C) ShakBN16/ShakBN16

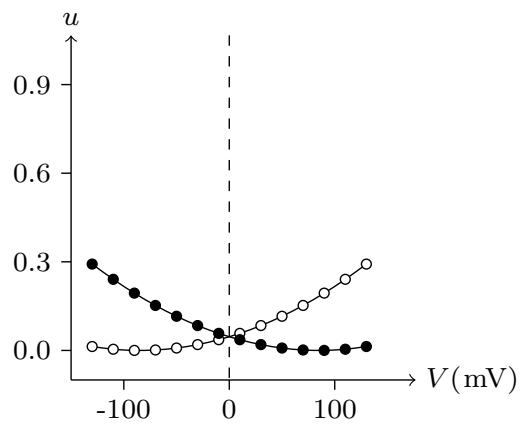

(B) ShakBL/ShakBL

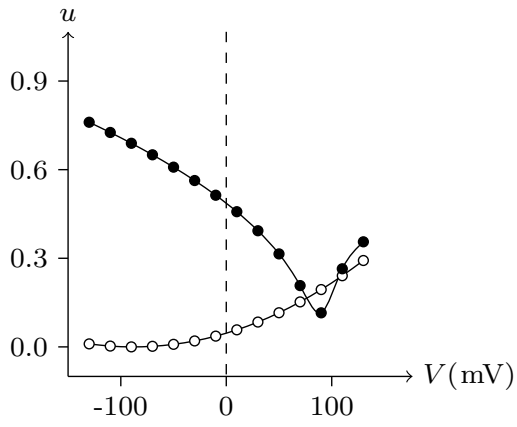

(D) ShakBL/ShakBN16

Figure 12: Interactions of docking hemichannels. The points are the values of the steadystate $\left(V_{\mathbf{j}}, u_{h}\right)$ and $\left(V_{\mathbf{j}}, u_{h_{\boldsymbol{q}}}\right)$ recorded in junctional channels $(h, h \boldsymbol{\Phi})$, white for $h$, black for $h$. All parameters are the same as above. 
relatively independent, then the voltage sensitivity of $(h, h \boldsymbol{\uparrow})$ is significant, such as ShakBL/ShakBL (see Figures 9 and 12B), and other connexin gap junctional channels in this paper (e.g. Cx32/Cx32, see Figures 4 and 12A). If both $u_{h}$ and $u_{h}$ are large, as the interaction between $h$ and $h$ is significant, the opening of one will prevent the closing of the other, and the closing of the one will also prevent the opening of the other. Particularly, when the two are in equilibrium, the junctional channel shows no voltage sensitivity. If $u_{h}$ is much greater than $u_{h}$, as the effect of $h$ on $h$ is much greater than that of $h \boldsymbol{q}$ on $h$, then the change of junctional channel permeability mainly depends on $h$, and vice versa. This explains why: the voltage sensitivity of ShakBN16/ShakBN16 homotypic junctional channels is not significant near $V_{\mathrm{j}}=$ $0 \mathrm{mV}$, and as $\left|V_{\mathrm{j}}\right|$ increases, steady-state $G_{\mathrm{j}}$ slightly rises. ShakBL/ShakBN16 is special, where almost $u_{\text {ShakBN16 }}>u_{\text {ShakBL }}$ except in the vicinity of $V_{\mathrm{j}}=90 \mathrm{mV}$, and $u_{\text {ShakBN16 }} \gg u_{\text {ShakBL for }} V_{\mathrm{j}}<0 \mathrm{mV}$ (see Figure 12D). So, in ShakBL/ShakBN16, ShakBN16 is dominant, especially in the range of $V_{\mathrm{j}}<0 \mathrm{mV}$. Thus, the $\left(V_{\mathrm{j}}, \overline{G_{\mathrm{j}}}\right)$ curve of ShakBL/ShakBN16 is inverse sigmoidal, as described above.

As observed, the nature of Innexin ShakB differs greatly from that of the connexin family. However, their physiological phenomena can be successfully simulated with the gap junctional channel model. Moreover, the parameters are unified without contradiction.

\subsubsection{Formed by Pannexins}

The properties of non-junctional Oocytes Px1 simulated and analysed above will not be repeated here.

Pannexins can form intercellular channels in paired oocytes. Pannexin 1 (Px1) alone and in combination with pannexin $2(\mathrm{Px} 2)$ can form intercellular channels. $\mathrm{Px} 1 / \mathrm{Px} 1$ pairs display a remarkable insensitivity to transjunctional voltage. At higher transjunctional voltage $\left(\left|V_{\mathrm{j}} / \mathrm{mV}\right| \gg 0\right)$, the conductance of pannexin intercellular channels displays a slight but brief reduction [9].

These phenomena (see Figure 26 for the actually recorded data), simulated in Figure 13, further demonstrate the applicability of the gap junction model.

By observing the interaction of the paired hemichannels $\left(\mathrm{Px} 1_{L}, P x 1_{R}\right)$ which for$\mathrm{m} \operatorname{Px} 1 / \mathrm{Px} 1$ junctional channels, it can be seen that for any $V_{\mathrm{j}}$, there is $u_{\mathrm{Px} 1_{\mathrm{L}}}=$ $u_{\mathrm{Px} 1_{\mathrm{R}}}=0.9$. The hemichannels on both sides almost completely lose their sensitivity, which is quite different from most hemichannels of connexin and innexin families (see Figure 14 for Cx32, ShakBL, ShakBN16 and Px1), and it is also the reason why $\mathrm{Px} 1 / \mathrm{Px} 1$ pairs appear to be almost insensitive to $V_{\mathrm{j}}$. 


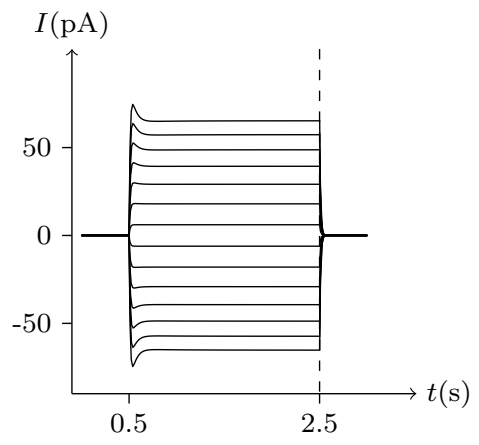

(A)

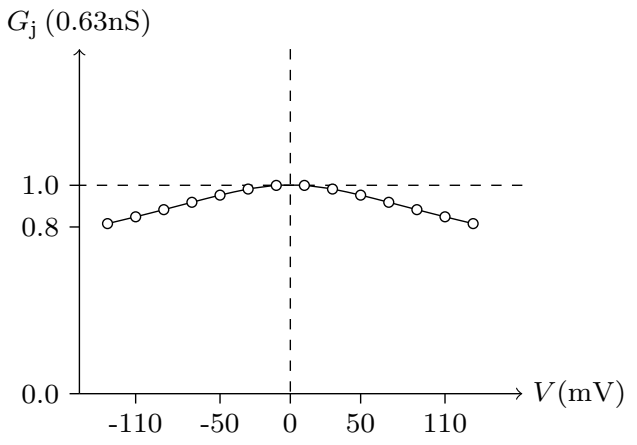

(B)

Figure 13: Simulation of $V_{\mathrm{j}}$ gating property of $\mathrm{Px} 1 / \mathrm{Px} 1$ junctional channels. Gap junctional channel: Px1/Px1. Internal and external solution: equal as in Figure 3. Patch clamps: $R_{\mathrm{s}(\mathrm{L})}=R_{\mathrm{s}(\mathrm{R})}=0.3 \mathrm{M} \Omega ; \Delta V_{\mathrm{s}}=0 \mathrm{mV}$ for $t / \mathrm{s} \notin[0.5,2.5), \Delta V_{\mathrm{s}}=-130 \mathrm{mV}$ to $+130 \mathrm{mV}$ for $t / \mathrm{s} \in[0.5,2.5)$. (A) Junctional currents induced by $V_{\mathrm{j}}$ pulses. (B) Graph of the steady-state $\left(V_{\mathrm{j}}, G_{\mathrm{j}}\right)$ relationship, where the points are recorded at $t=2.5 \mathrm{~s}$.

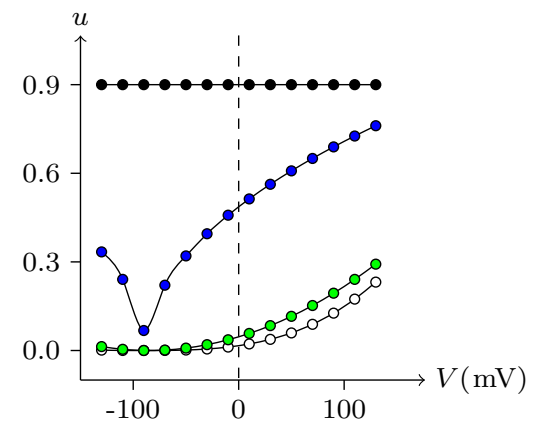

Figure 14: Interactions of symmetrical docking hemichannels. Because of symmetry, only one side of the data are shown here. The points are the values of the steady-state $\left(V_{\mathrm{j}}, u_{h}\right)$ recorded in junctional channels, white for $\mathrm{Cx} 32 / \mathrm{Cx} 32$, green for ShakBK/ShakBL, blue for ShakBN16/ShakBN16, black for Px1/Px1. All parameters are the same as above. 


\subsubsection{Permeability}

Ion substitution is generally used to study the selective permeability of channels.

Scholars often choose to substitute anions significantly different in size or aqueous mobility, such as glutamate, which has only one-fifth the aqueous mobility of chloride.

Results of physiological experiments indicated that, although Cx32 channels mainly transport cations, they are also permeable to $\mathrm{Cl}^{-}$(see Figure 27) [21].

Ion permeabilities of hemichannels and gap junctional channels can be calculated (see Table 2) by fitting the permeability curves of our model (see Figure 15). Essentially, the permeability of junctional channel $(h, h \mathbf{q})$ depends on the permeabilities of hemichannels $h$ and $h$.

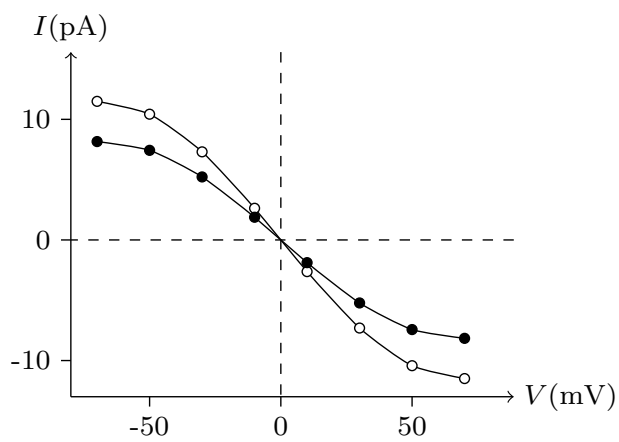

Figure 15: Numerical simulation of the experiments to study the permeability of $\mathrm{Cx} 32 / \mathrm{Cx} 32$ junctions to $\mathrm{Cl}^{-}$. White points (junctional currents and voltages) are recorded at $t=20 \mathrm{~s}$ in the experiment of Figure 4. Replacing $\mathrm{KCl}$ with K-glu, while keeping the other parameters constant, allows obtaining the black points. 


\subsubsection{Signal Transmission}

The docking between hemichannels forms gap junctions that allow the passage of ions, generating communication. However, there is no model to describe how variations in hemichannel assembly can generate the variety of communication properties of gap junctions.

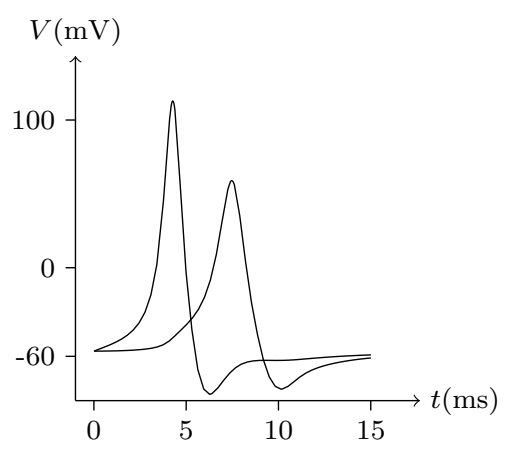

Figure 16: Numerical simulation of time delay and attenuation of signal transmission via Cx36/Cx36 junction. Gap junction: Cx36/Cx36. Ion channel list of cell $\mathrm{L}$ and $\mathrm{R}: \mathrm{Na}_{\mathrm{v}}$, $\mathrm{K}_{\mathrm{v}}, \mathrm{Cl}_{\mathrm{v}}$. Internal solution: I-4. External solution: E-1. Patch clamp impaling cell L: $\imath_{\mathrm{s}}=0.05 \mathrm{~A} / \mathrm{m}^{2}$ for $t / \mathrm{ms} \in[0,5), \imath_{\mathrm{s}}=0 \mathrm{~A} / \mathrm{m}^{2}$ for $t / \mathrm{ms} \notin[0,5)$.

Electrical synapses are often considered symmetrical structures, with presynaptic and postsynaptic sites considered as mirror images of each other. In mammals, Cx36 is widely expressed in neurons [22], which only forms homotypic intercellular channels [23]. Figures 16 and 17 simulate signal transmission by Cx36/Cx36 junction.

It has been reported that $\mathrm{Cx} 35$ and $\mathrm{Cx} 34.7$ can form heterotypic junctions, with Cx35 expressed presynaptically and Cx34.7 expressed postsynaptically [24]. Asymmetry in the molecular composition of adjoining connexons allows electrical rectification at some gap junctions [14]. Thus, molecular asymmetries in gap junctions underpin the complexity of their functional properties, and suggest that the signal transmission of electrical synapses is not necessarily symmetrical. This difference has been observed in simultaneous recordings in physiological experiments [24]. As mentioned above, connexins mediating gap junctional intercellular communication in retinal pigment epithelial cells have been identified as $\mathrm{Cx} 43$ and $\mathrm{Cx} 46$. With the parameters employed, we went onto simulate the non-mirrored signal transmission of $\mathrm{Cx} 43 / \mathrm{Cx} 46$ junctions, as illustrated in Figure 18. Also, the delay of electrical signal transmission in numerical experiments of heterotypic junctions is evident, which can be observed in electrophysiological experiments [25]. 


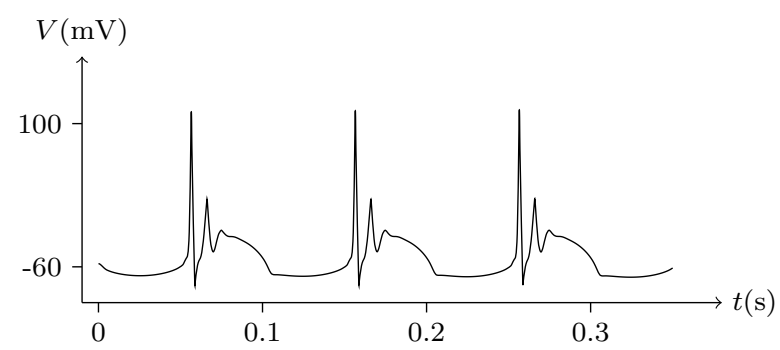

(A)

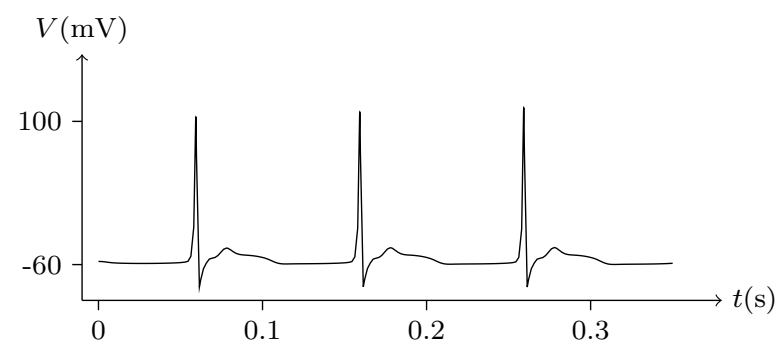

(B)

Figure 17: Numerical simulation of bursting signal transmission via $\mathrm{Cx} 36 / \mathrm{Cx} 36$ junction. Patch clamp impaling cell L: $\iota_{\mathrm{s}}=-0.2 \mathrm{~A} / \mathrm{m}^{2} \cdot \sin 20 \pi t / \mathrm{s}$. Gap junction: $\mathrm{Cx} 36 / \mathrm{Cx} 36$. Ion channel list of cell $\mathrm{L}$ and $\mathrm{R}: \mathrm{Na}_{\mathrm{v}}, \mathrm{K}_{\mathrm{v}}, \mathrm{Cl}_{\mathrm{v}}$. Internal solution: I-4. External solution: E-1. (A) Membrane potential of cell L. (B) Membrane potential of cell R.

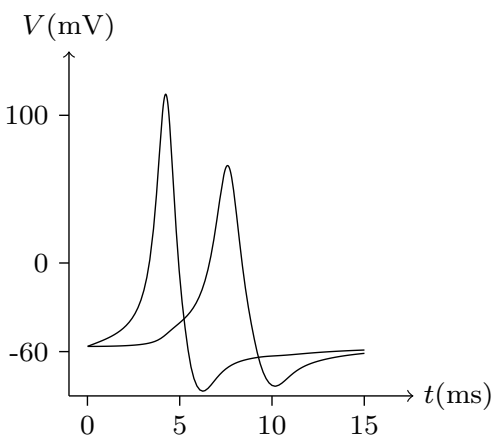

(A)

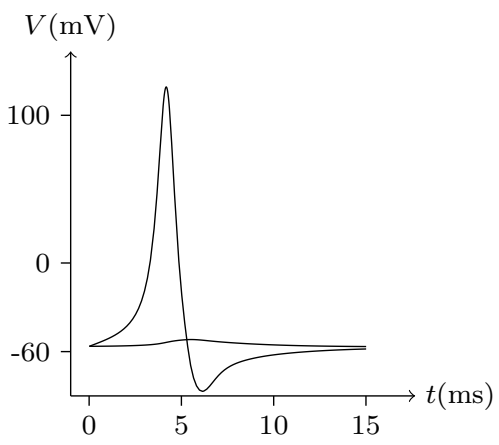

(B)

Figure 18: Numerical simulation signal transmission via $\mathrm{Cx} 43 / \mathrm{Cx} 46$ junction. Gap junction: $\mathrm{Cx} 43 / \mathrm{Cx} 46$. Ion channel list of cell $\mathrm{L}$ and $\mathrm{R}: \mathrm{Na}_{\mathrm{v}}, \mathrm{K}_{\mathrm{v}}, \mathrm{Cl}_{\mathrm{v}}$. Internal solution: I-4. External solution: E-1. (A) Patch clamp impaling cell L (expressing Cx43): $\iota_{\mathrm{s}}=0.05 \mathrm{~A} / \mathrm{m}^{2}$ for $t / \mathrm{ms} \in[0,5), \iota_{\mathrm{s}}=0 \mathrm{~A} / \mathrm{m}^{2}$ for $t / \mathrm{ms} \notin[0,5)$. (B) Patch clamp impaling cell $\mathrm{R}$ (expressing $\mathrm{Cx} 46): \imath_{\mathrm{s}}=0.05 \mathrm{~A} / \mathrm{m}^{2}$ for $t / \mathrm{ms} \in[0,5), \imath_{\mathrm{s}}=0 \mathrm{~A} / \mathrm{m}^{2}$ for $t / \mathrm{ms} \notin[0,5)$. 


\section{Conclusion}

Electrical synaptic transmission is considered an essential form of interneuronal communication, which is mediated by gap junctions. This method of communication is considered a form of direct transmission. Gap junctions transfer ions and other small molecules but not electrons, like the plasmodesmata of plants and septal pores of fungi. Electrical signal transmission is the result of ion transmission. Thus, a rational model should be able to describe and simulate the ion flow via gap junctions. Furthermore, each gap junctional channel is formed by the docking of hemichannels, which can be voltage gated by depolarisation in the non-junctional plasma membrane. Moreover, most unpaired hemichannels are functional.

However, a proper model for these functionalities is lacking. And no models have yet been able to correlate the two distinct gating mechanisms of hemichannels and junctional channels.

This study verified the applicability of the passive transmembrane ion transport model to hemichannels in non-junctional plasma membranes after simulating the typical electrophysiological phenomena of hemichannels, such as activation and ion blockage of unpair hemichannels. Moreover, by model-fitting studies, we can obtain detailed parameters, some of which cannot directly be measured in electrophysiological experiments, but can reveal several properties of unpaired hemichannels. For example, the sensitivity parameters indicate that $\mathrm{Cx} 32$ hemichannels are sensitive to intracellular $\mathrm{Ca}^{2+}$, while being even more sensitive to intracellular $\mathrm{Mg}^{2+}$. Another example is the filter parameters that indicate the function of unpaired Px1 channels on ion transport is different from that of Cxs and Ixs, which is reflected in the change in ion selectivity after activation.

On this basis, we have established a gap junctional channel model, which describes the docking of hemichannels, and simulates the homotypic and heterotypic gap junctions formed by connexins, innexins and pannexins. Comparing the simulation results with the actual measurement data, we believe that this model is widely applicable for multiple types of gap junctions, even though the molecular structures and electrophysiological properties of Cxs, Ixs and Pxs differ. It also indicates that the gating mechanism of junctional channels is completely determined by docking hemichannels and can be calculated. Using this model, electrical signal transmission can be simulated successfully, where signal attenuation and delay can be observed. In particular, the non-mirrored signal transmission can be observed in numerical experiments of heterotypic junctions. These results that are consistent with the phenomenon of electrophysiological experiments, indicate that the proposed model is widely applicable to different types of gap junctions. 
472 In summary, our work unified the gating mechanisms of hemichannels and gap 473 junctional channels which were previously considered unrelated, and explained their 474 associated electrophysiological properties based on ion passivity transport. Some 475 properties that cannot be directly observed by electrophysiological experiments can 476 be reasonably inferred by our model, which may provide clues for us to further explore 477 the physiological functions of hemichannels and junctional channels.

\section{${ }_{478} 6$ Author Contributions}

${ }_{479}$ QW: Conceptualisation, software and writing; SL: Supervision.

\section{${ }_{480} 7$ Acknowledgments}

${ }_{481}$ The project is supported in part by the National Natural Science Foundation of 482 China (Grant Nos. 11872183 and 11572127).

${ }_{496}$ Temperature $=310 \mathrm{~K}$, membrane thickness $=6 \mathrm{~nm}$, relative membrane permittivity ${ }_{497}=7$, radius $=50 \mu \mathrm{m}$.

\section{Appendix}

\subsection{Solution}

The solution of numerical experiments in this study (in mmol/L): [I-1] $\mathrm{NaCl} 2, \mathrm{KCl}$ $92, \mathrm{Mg}(\mathrm{OH})_{2}$ 0.5, Ca-EGTA 1 ; [I-2] $\mathrm{NaCl} 1, \mathrm{KCl} 90, \mathrm{Ca}(\mathrm{NO})_{3}$ 0.75; [I-3] $\mathrm{NaCl} 2, \mathrm{KCl}$ 92, $\mathrm{Mg}(\mathrm{OH})_{2}$ 0.5, Ca-EGTA 2; [I-4] $\mathrm{NaCl}$ 9, NaOH 1, KCl 120, CsCl 1, Ca-EGTA $1, \mathrm{MgCl}_{2} 2$; [E-1] $\mathrm{NaCl} 139, \mathrm{NaOH} 1, \mathrm{KCl} 5, \mathrm{CsCl} 1$, Ca-EGTA $1, \mathrm{MgCl}_{2}$ 1; [ND96] $\mathrm{NaCl} 96, \mathrm{KCl} 2, \mathrm{Mg}(\mathrm{OH})_{2}$ 1, Ca-EGTA 1.8; [ND96-1] $\mathrm{NaCl} 96, \mathrm{KCl} 2$, Ca-EGTA 0.5; [ND96-2] NaCl 96, KCl 2, Ca-EGTA 5; [Barth's] NaCl 88, $\mathrm{KCl} 1, \mathrm{NaHCO}_{3} 2.4$, $\mathrm{Ca}\left(\mathrm{NO}_{3}\right)_{2}$ 0.33, $\mathrm{CaCl}_{2}$ 0.41, $\mathrm{MgSO}_{4} 0.82$.

\subsection{Ion Parameters}

The ionic radiuses (pm) used in the numerical simulations: $\mathrm{Na}^{+} 102, \mathrm{Mg}^{2+} 72, \mathrm{Cl}^{-}$ $181, \mathrm{~K}^{+} 138, \mathrm{Ca}^{2+} 100, \mathrm{Cs}^{+} 167, \mathrm{OH}^{-} 137$.

\subsection{Cell Parameters}




\subsection{Channel Parameters}

All the parameters of the passive transmembrane ion transport model are recorded in Tables 1-4, of which the definitions can be found in our previous paper [15]. The parameters of the gap junction model are recorded in Table 5. The parameters unassigned in appendix, defaults to 0 .

\subsection{Appended Figures}

The actual recorded data of the electrophysiological experiments corresponding to the numerical simulation results in this paper would be seen in Figures 19-27.

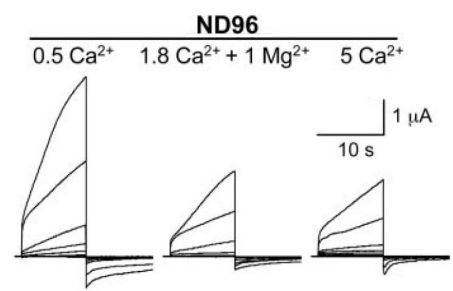

Figure 19: The Electrophysiological experimental data of that external $\mathrm{Ca}^{2+}$ blocks voltagegated opening of human Cx32 hemichannels. Activating outward currents evoked by depolarising pulses from -40 to $120 \mathrm{mV}$ in isolated $\mathrm{Cx} 32$ Xenopus oocytes exposed to normal $\left(\mathrm{ND} 96,\left[\mathrm{Ca}^{2+}\right]=1.8 \mathrm{mM}\right.$ and $\left.\left[\mathrm{Mg}^{2+}\right]=1 \mathrm{mM}\right)$, low $(0.5 \mathrm{mM})$ and high $\mathrm{Ca}^{2+}(5 \mathrm{mM})$ solutions. Cited from [17], The corresponding numerical simulation is shown in Figure 1.

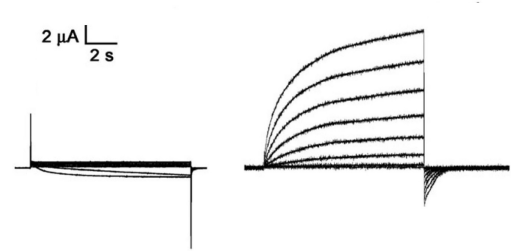

(A)

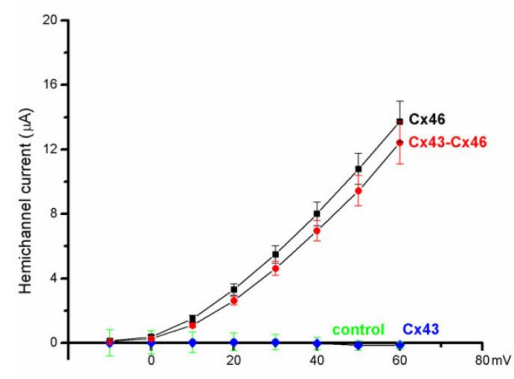

(B)

Figure 20: Membrane currents recorded from single cells expressing $\mathrm{Cx} 43$ and $\mathrm{Cx} 46$ individually in response to depolarising voltage steps from a holding potential of $-20 \mathrm{mV}$, and stepped in $10 \mathrm{mV}$ increments from $-10 \mathrm{mV}$ to $60 \mathrm{mV}$. Cited from [20]. 


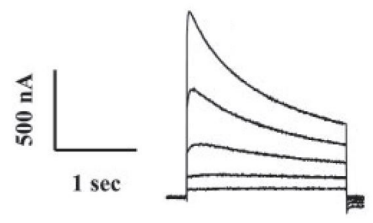

Figure 21: Whole-cell membrane currents measured from single oocytes expressing Px1. Cells were initially clamped at a membrane potential of $-40 \mathrm{mV}$, and depolarising steps lasting $2 \mathrm{sec}$ were applied in 10-mV increments up to $60 \mathrm{mV}$. Cited from [9].

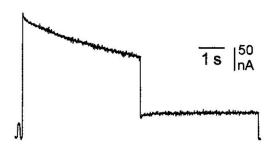

(A)

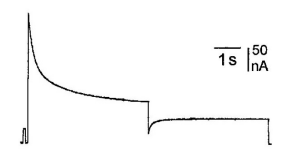

(B)

Figure 22: The Electrophysiological experimental data of the comparison between (A) Cx32/Cx32 and (B) Cx43/Cx43 gap junctional channels. Cited from [19].
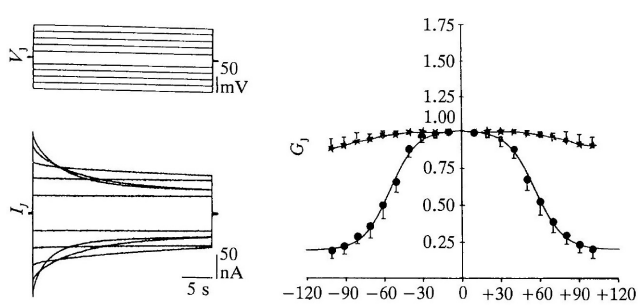

Figure 23: Junctional current data recorded from paired oocytes Cx32/Cx32. The left column shows junctional voltage and examples of current traces. The right column plots $(\bullet)$ normalised steady-state junctional conductances. Cited from [26]. 


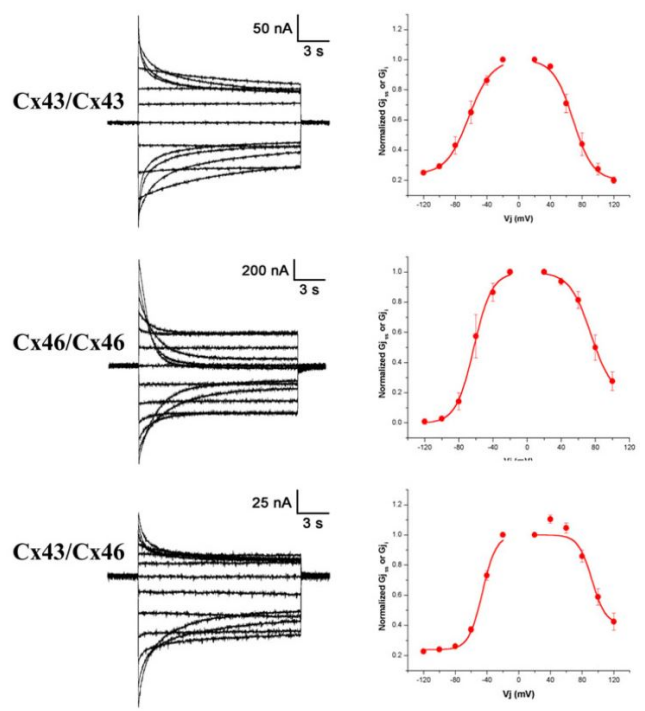

Figure 24: Junctional current data recorded from paired oocytes $\mathrm{Cx} 43 / \mathrm{Cx} 43, \mathrm{Cx} 46 / \mathrm{Cx} 46$ and $\mathrm{Cx} 43 / \mathrm{Cx} 46$. The left column shows examples of current traces. The right column plots normalised steady-state junctional conductances. Cited from [20].
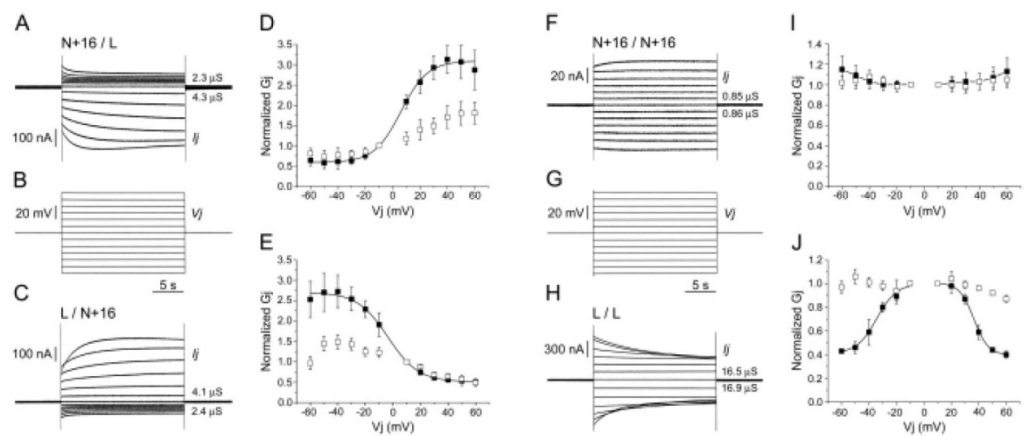

Figure 25: Current traces and voltage sensitivity of ShakB junctions. (A, C) Currents induced in Xenopus oocytes expressing ShakBN16 and ShakBL, and the voltage pulse protocol is shown in Fig. 25B. (D, E) The relationship between junctional voltage and junctional conductance. (F) Currents induced by a ShakBN16-ShakBN16 homotypic pairing, and the voltage pulse protocol is shown in Fig. 25G. (H) Currents induced by a ShakBL-ShakBL homotypic pairing, and the voltage pulse protocol is shown in in Fig. 25G. (I) The relationship between junctional voltage and junctional conductance for ShakBN16-ShakBN16 homotypic pairings. $(\mathrm{J})$ The relationship between junctional voltage and junctional conductance for ShakBL-ShakBL homotypic pairings. Cited from [27]. 


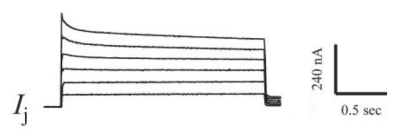

Figure 26: Functional expression of Px1 in paired oocytes. Junctional currents $\left(I_{\mathrm{j}}\right)$ were recorded from oocyte pairs in response to depolarising $V_{\mathrm{j}}$ steps (bottom traces) applied, from a holding potential of $-40 \mathrm{mV}$, in $20-\mathrm{mV}$ increments, to $120 \mathrm{mV}$. Cited from [9].

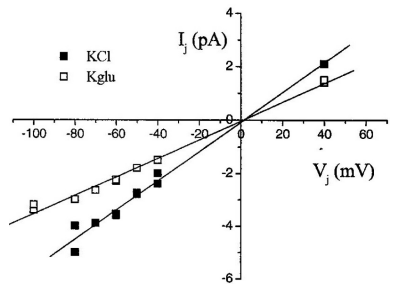

Figure 27: Homotypic N2A cell pairs exposed to either $120 \mathrm{mM} \mathrm{KCl}$ or $120 \mathrm{mM}$ Kglutamate electrode solutions. Cited from [21]. 


\section{References}

[1] R. Bruzzone, T. W. White, D. L. Paul, Connections with connexins: the molecular basis of direct intercellular signaling, European Journal of Biochemistry 238 (1) (1996) 1-27.

[2] Harris, A. L., Kinetic properties of a voltage-dependent junctional conductance, Journal of General Physiology 77 (1) (1981) 95-117.

[3] Paul, L. D., Connexin46, a novel lens gap junction protein, induces voltage-gated currents in nonjunctional plasma membrane of xenopus oocytes, Journal of Cell Biology 115 (4) (1991) 1077-1089.

[4] D. A. Goodenough, D. L. Paul, Beyond the gap: functions of unpaired connexon channels, Nat Rev Mol Cell Biol 4 (4) (2003) 285-295.

[5] G. E. Sosinsky, D. Boassa, R. Dermietzel, H. S. Duffy, D. W. Laird, B. Macvicar, C. C. Naus, S. Penuela, E. Scemes, D. C. a. Spray, Pannexin channels are not gap junction hemichannels, Channels 5 (3) (2011) 193-197.

[6] A. Oshima, K. Tani, Y. Fujiyoshi, Atomic structure of the innexin-6 gap junction channel determined by cryo-em, Nature Communications 7 (2016) 13681.

[7] M. Raff, B. Alberts, J. Lewis, A. Johnson, K. Roberts, Molecular biology of the cell 4th edition, Artificial Life 10 (2) (2002) 82-95.

[8] P. Phelan, Innexins: members of an evolutionarily conserved family of gapjunction proteins, Biochimica Et Biophysica Acta 1711 (2) (2005) 0-245.

[9] R. Bruzzone, S. G. Hormuzdi, M. T. Barbe, A. Herb, H. Monyer, Pannexins, a family of gap junction proteins expressed in brain, PNAS 100 (23) (2003) 13644-13649.

[10] R. Qu, L. Dong, J. Zhang, X. Yu, L. Wang, S. Zhu, Cryo-em structure of human heptameric pannexin1 channel, Cell Research.

[11] A. L. Harris, Emerging issues of connexin channels: biophysics fills the gap, Quarterly Reviews of Biophysics 34 (03).

[12] Hornstein, Eric, P., Verweij, Jan, Peter, H., Li, Schnapf, Julie, Gap-junctional coupling and absolute sensitivity of photoreceptors in macaque retina., Journal of Neuroscience 25 (48) (2005) 11201-11209.

[13] A. C. Miller, A. C. Whitebirch, A. N. Shah, K. C. Marsden, M. Granato, J. O'Brien, C. B. Moens, A genetic basis for molecular asymmetry at vertebrate electrical synapses, eLife 6 . 
[14] P. Phelan, L. A. Goulding, J. L. Y. Tam, M. J. Allen, R. J. Dawber, J. A. Davies, J. P. Bacon, Molecular mechanism of rectification at identified electrical synapses in the drosophila giant fiber system, Current Biology Cb 18 (24) (2009) $1955-1960$.

[15] Q. Wang, S. Liu, A general model of ion passive transmembrane transport based on ionic concentration, Frontiers in Computational Neuroscience 12 (110).

[16] D, C, Spray, A, L, Harris, M, V, Bennett, Equilibrium properties of a voltagedependent junctional conductance, The Journal of general physiology.

[17] G.-H. JM., M. MC., B. Larrosa, D. Gonzalez, B. LC., Molecular basis of calcium regulation in connexin-32 hemichannels, Proceedings of the National Academy of Sciences of the United States of America 100 (26) (2003) 16030-16035.

[18] E. D. Vuyst, W. Nan, E. Decrock, M. D. Bock, M. Vinken, M. V. Moorhem, C. Lai, M. Culot, V. Rogiers, R. Cecchelli, Ca2+ regulation of connexin 43 hemichannels in c6 glioma and glial cells, Cell Calcium 46 (3) (2009) 176-187.

[19] A. Revilla, C. Castro, L. C. Barrio, Molecular dissection of transjunctional voltage dependence in the connexin-32 and connexin-43 junctions, Biophysical Journal 77 (1999) 1374-1383.

[20] V. H. Quan, H. Qian, H. Ripps, Functional analysis of hemichannels and gapjunctional channels formed by connexins 43 and 46, Molecular Vision 16 (2010) $1343-1352$.

[21] T. M. Suchyna, J. M. Nitsche, M. Chilton, A. L. Harris, R. D. Veenstra, B. J. Nicholson, Different ionic selectivities for connexins 26 and 32 produce rectifying gap junction channels, Biophysical Journal 77 (1999) 29682987.

[22] M. L. Steyn-Ross, D. A. Steyn-Ross, J. W. Sleigh, Gap junctions modulate seizures in a mean-field model of general anesthesia for the cortex, Cognitive Neurodynamics 6 (3) (2012) 215-225.

[23] B. Teubner, J. Degen, G. Sohl, M. Guldenagel, F. F. Bukauskas, E. B. Trexler, V. K. Verselis, C. I. D. Zeeuw, C. G. Lee, C. A. Kozak, Functional expression of the murine connexin 36 gene coding for a neuron-specific gap junctional protein, Journal of Membrane Biology 176 (3) (2000) 249-262.

[24] J. R. Rash, S. Curti, K. G. V. V. et al., Molecular and functional asymmetry at a vertebrate electrical synapse, Neuron 79 (5) (2013) 957-969.

[25] C. Giaume, H. Korn, Voltage-dependent dye coupling at a rectifying electrotonic synapse of the crayfish, J. Physiol. 356 (1984) 151-167. 
[26] L. C. Barrio, T. Suchyna, T. Bargiello, L. X. Xu, R. S. Roginski, M. V. Bennett, B. J. Nicholson, Gap junctions formed by connexins 26 and 32 alone and in combination are differently affected by applied voltage, Proceedings of the National Academy of Sciences.

[27] W. Marks, Structural analysis of the drosophila innexin shakb: Role of the nterminus in rectifying electrical synapses, American Journal of Medical Genetics Part B Neuropsychiatric Genetics 153B (7) (2012) 1311-7.

Table 1: Filter state parameters

\begin{tabular}{l|c|ccccc}
\hline \multirow{2}{*}{$h$} & \multirow{2}{*}{$\gamma_{h}\left(\mathrm{~s}^{-1}\right)$} & \multicolumn{5}{|c}{$\kappa_{h, i}$} \\
\cline { 3 - 7 } & $\mathrm{Na}^{+}$ & $\mathrm{K}^{+}$ & $\mathrm{Cs}^{+}$ & $\mathrm{Ca}^{2+}$ & $\mathrm{Cl}^{-}$ \\
\hline Cx32 & - & - & - & - & - & - \\
Cx36 & - & - & - & - & - & - \\
Cx43 & - & - & - & - & - & - \\
Cx46 & - & - & - & - & - & - \\
ShakBL & - & - & - & - & - & - \\
ShakBN16 & - & - & - & - & - & - \\
Px1 & 2.0 & 12 & 16 & - & - & 16 \\
\hline
\end{tabular}

Table 2: Standard selective permeability $\varrho_{h, i}\left(\mathrm{~ms}^{-1}\right)$ of filter

\begin{tabular}{l|ccccc}
\hline \multicolumn{1}{c}{${ }^{r}$} & $\mathrm{Na}^{+}$ & $\mathrm{K}^{+}$ & $\mathrm{Ca}^{2+}$ & $\mathrm{Mg}^{2+}$ & $\mathrm{Cl}^{-}$ \\
\hline $\mathrm{Cx} 32$ & 0.50 & 0.40 & 0.40 & 0.40 & 0.10 \\
$\mathrm{Cx} 36$ & 0.52 & 0.40 & 0.40 & 0.40 & 0.10 \\
$\mathrm{Cx} 43$ & 0.15 & 0.10 & 0.10 & 0.10 & 0.01 \\
$\mathrm{Cx} 46$ & 0.52 & 0.40 & 0.40 & 0.40 & 0.10 \\
ShakBL & 0.52 & 0.40 & 0.40 & 0.40 & 0.10 \\
ShakBN16 & 0.52 & 0.40 & 0.40 & 0.40 & 0.10 \\
Px1 & 0.45 & 0.40 & 0.40 & 0.40 & 0.10 \\
$\mathrm{Na}_{\mathrm{v}}$ & 100 & 10 & - & - & - \\
$\mathrm{K}_{\mathrm{v}}$ & - & 20 & - & - & - \\
$\mathrm{Cl}_{\mathrm{v}}$ & - & - & - & - & 10 \\
\hline
\end{tabular}


Table 3: Properties of gate and sensor

\begin{tabular}{l|cccccc}
\hline$h$ & $\alpha_{h}\left(\mathrm{~s}^{-1}\right)$ & $\beta_{h} /\left(1+\delta_{h}\right)\left(\mathrm{s}^{-1}\right)$ & $\delta_{h}$ & $\bar{\sigma}_{h}\left(\mathrm{nmol} / \mathrm{m}^{2}\right)$ & $\tau_{h} /\left(\varrho_{h} \cdot \boldsymbol{s}_{h}\right)$ & $\eta_{h}$ \\
\hline $\mathrm{Cx} 32$ & 0.5 & 2.0 & 10 & 0.120 & 50 & 3.0 \\
$\mathrm{Cx} 36$ & 1.0 & 3.0 & 100 & 0.130 & 50 & 3.0 \\
$\mathrm{Cx} 43$ & 2.0 & $3.0 \times 10^{3}$ & $1.0 \times 10^{-3}$ & 0.135 & 100 & 3.0 \\
$\mathrm{Cx} 46$ & 1.2 & 5.0 & 2.0 & 0.135 & 50 & 3.0 \\
ShakBL & 6.0 & $6.0 \times 10^{3}$ & $1.0 \times 10^{-2}$ & 0.135 & 50 & 3.0 \\
ShakBN16 & 6.0 & $6.0 \times 10^{3}$ & $1.0 \times 10^{-2}$ & 0.135 & 50 & 3.0 \\
$\mathrm{Px} 1$ & 20 & 20 & 100 & 0.36 & 50 & 3.0 \\
$\mathrm{Na}$ & $5.0 \times 10^{3}$ & $5.0 \times 10^{4}$ & $5.0 \times 10^{-3}$ & 1.9 & $1.0 \times 10^{6}$ & 5.0 \\
$\mathrm{~K}_{\mathrm{v}}$ & $5.0 \times 10^{2}$ & $5.0 \times 10^{4}$ & $5.0 \times 10^{-3}$ & 30 & $1.0 \times 10^{6}$ & 2.0 \\
$\mathrm{Cl}_{\mathrm{v}}$ & $1.0 \times 10^{3}$ & $5.0 \times 10^{4}$ & $5.0 \times 10^{-3}$ & 56 & $1.0 \times 10^{6}$ & 2.0 \\
\hline
\end{tabular}

The sensitivity and permeability parameters of inductor are shown in Tables 2 and 4 .

Table 4: Sensitivity parameters $s_{h, i}$

\begin{tabular}{l|ccccc}
\hline \multicolumn{1}{c|}{${ }^{i}$} & $\mathrm{Na}^{+}$ & $\mathrm{K}^{+}$ & $\mathrm{Ca}^{2+}$ & $\mathrm{Mg}^{2+}$ & $\mathrm{Cl}^{-}$ \\
\hline $\mathrm{Cx} 32$ & - & - & 0.3 & 1.0 & - \\
$\mathrm{Cx} 36$ & - & - & 1.0 & - & - \\
$\mathrm{Cx} 43$ & - & - & 1.0 & 1.0 & - \\
$\mathrm{Cx} 46$ & - & - & 1.0 & - & - \\
$\mathrm{ShakBL}$ & - & - & 1.0 & - & - \\
$\mathrm{ShakN} 16$ & - & - & 1.0 & - & - \\
$\mathrm{Px} 1$ & - & - & 1.0 & - & - \\
$\mathrm{Na}$ & 1.0 & - & - & - & - \\
$\mathrm{K}_{\mathrm{v}}$ & - & 1.0 & - & - & - \\
$\mathrm{Cl}_{\mathrm{v}}$ & - & - & - & - & 1.0 \\
\hline
\end{tabular}

Table 5: Junction parameters

\begin{tabular}{c|cc|cc}
\hline junction $(h, h \boldsymbol{q})$ & $\varpi_{h}$ & $n_{h}$ & $\varpi_{h \boldsymbol{q}}$ & $n_{h \boldsymbol{q}}$ \\
\hline Cx32/Cx32 & 19. & 3.0 & 19. & 3.0 \\
Cx36/Cx36 & 3.0 & 2.0 & 3.0 & 2.0 \\
Cx43/Cx43 & 4.0 & 2.0 & 4.0 & 2.0 \\
Cx46/Cx46 & 13. & 3.0 & 13. & 3.0 \\
Cx43/Cx46 & 4.0 & 2.0 & 13. & 3.0 \\
ShakBL/ShakBL & 4.2 & 2.0 & 4.2 & 2.0 \\
ShakBN16/ShakBN16 & 1.5 & 0.5 & 1.5 & 0.5 \\
ShakBL/ShakBN16 & 4.2 & 2.0 & 1.5 & 0.5 \\
Px1/Px1 & 0.9 & 0.0 & 0.9 & 0.0 \\
\hline
\end{tabular}

